\title{
LA ESTRUCTURA DE LA COMERCIALIZACIÓN, FINANCIAMIENTO Y TRANSPORTE DE LOS PRINCIPALES PRODUCTOS AGRÍCOLAS Y SU RENTABILIDAD PARA LOS AGRICULTORES DEL CANTÓN GUAMOTE
}

\author{
THE STRUCTURE OF COMMERCIALIZATION, \\ FINANCING, AND TRANSPORTATION OF MAIN \\ AGRICULTUAL PRODUCTS AND THEIR PROFITABILITY \\ FOR FARMERS OF GUAMOTE CANTON
}

\section{ALFREDO ALTAMIRANO ULLOA MAYRA BELTRÁN MORALES}

Recibido 10 de junio del 2016 Aceptado 2 de septiembre del 2016 

Revista PUCE. ISSN 1390-7719. Núm.103. 3 de mayo de 2016-

3 de noviembre de 2016. Alfredo Altamirano Ulloa, Mayra Beltrán MORALES. PP. $185-231$

\title{
LA ESTRUCTURA DE LA COMERCIALIZACIÓN, FINANCIAMIENTO Y TRANSPORTE DE LOS PRINCIPALES PRODUCTOS AGRÍCOLAS Y SU RENTABILIDAD PARA LOS AGRICULTORES DEL CANTÓN GUAMOTE
}

\author{
THE STRUCTURE OF COMMERCIALIZATION, \\ FINANCING, AND TRANSPORTATION OF MAIN \\ AGRICULTUAL PRODUCTS AND THEIR PROFITABILITY \\ FOR FARMERS OF GUAMOTE CANTON
}

PALABRAS CLAVE: Rentabilidad agrícola, financiamiento, comercialización, intermediación, transporte

KEY WORDS: Agricultural profitability, financing, commercialization, intermediation, transportation

\section{RESUMEN}

Desde una perspectiva histórica, Guamote formó parte de la villa de Riobamba como parroquia eclesiástica desde 1613 y parroquia civil desde 1643; en 1944, durante el gobierno del Dr. José María Velasco Ibarra, se cantoniza mediante decreto ejecutivo 606. Se localiza en el callejón interandino al sur de Quito, en la vía a Cuenca a 50 Km. de Riobamba. Se integra por 3 parroquias: Guamote o Matriz (urbana) con 54 comunidades, 5 asociaciones, 1 cooperativa y 7 barrios urbanos; Cebadas (rural) la más extensa y la menos poblada con 19 comunida- 
des, 10 asociaciones y 1 cooperativa y 1 cabecera parroquial; y Palmira (rural) conformada por 23 comunidades, 9 asociaciones, 2 cooperativas y 1 cabecera parroquial;

El agricultor del cantón es vulnerable porque el sistema de producción imperante se concentra en pocos productos transitorios y una fragmentada propiedad de la tierra en parcelas pequeñas, lo cual estaría incidiendo en el volumen de producción y consecuentemente en los ingresos familiares. En estas condiciones la población no puede satisfacer necesidades básicas como una adecuada alimentación, educación y salud; a pesar de la ejecución de proyectos y programas que impulsan varios actores como la Iglesia, cooperación nacional e internacional y entidades públicas de los gobiernos central y local, que no logran cambiar las condiciones de pobreza existentes.

La columna vertebral de la conectividad cantonal es la vía panamericana que se complementa con la Vía a la Costa que une las dos regiones que facilita el acceso a otros mercados mayoris- tas. Sin embargo, en el escenario interno, la conectividad entre las comunidades y desde las comunidades a los centros de acopio tiene dificultades por las vías que son construidas y mantenidas en parte por las comunidades a través del sistema de mingas. Adicionalmente, las distancias heterogéneas y la topografía tan difícil, juegan un papel en contra de ciertas comunidades pues generan inequidades para su acceso y movilidad de productos e insumos que impactan en la capacidad de satisfacer sus necesidades básicas.

Aproximadamente la mitad de la producción se concentra en papa, maíz suave choclo y haba, el resto se distribuye en una variedad de productos con volúmenes marginales. En este escenario, la rentabilidad la capta el intermediario quien no asume riesgos, pues la comercialización se realiza en la feria de Guamote, sitio al cual llega el agricultor luego de una larga etapa de trabajo de siembra, cuidado, cosecha y transporte que se ve afectada por condiciones externas a su control.

\section{ABSTRACT}

From a historical perspective, Guamote formed part of the village of Riobamba as an ecclesiastic parish since 1613, and a civil parish since 1643; in 1944, during the government of Dr. José María Velasco Ibarra, it became a canton through executive decree 606. It is located in the interandean section to the south of Quito, on the way to Cuenca, 50 kilometers from Riobamba. It is formed by three parishes: Guamote or Matriz (urban) with 54 communities, 5 associa- 
Revista PUCE. ISSN 1390-7719. Núm.103. 3 de mayo de 2016 -

3 De noviembre de 2016. Alfredo Altamirano UlLoa, Mayra Beltrán MORALES. PP. $185-231$

tions, 1 cooperative, and 7 urban neighborhoods; Cebadas (rural), the most extensive and less populated with 19 communities, 10 associations, 1 cooperative, and 1 parish head; and Palmira (rural) with 23 communities, 9 associations, 2 cooperatives, and 1 parish head.

The canton farmer is vulnerable because the prevailing production system is concentrated in a few transitory products and a fragmented land property of small parcels, which afects the production volume, and consequently family incomes. Under these conditions, the majority of the population cannot satisfy their basic needs, such as adequate food, education, and health, regardless of the execution of projects and programs launched by a number of social actors, such as the Church, national and international cooperation and public entities of central and local governments, that are not able to change existing poverty conditions.

The vertebral column of cantonal connectivity is the Panamerican highway that connects with the Way to the
Coast which unites two regions, facilitating access to other wholesale markets. Nevertheless, within the internal scenario, connectivity between communities and from communities to supply centers is difficult as the roads are constructed and maintained partially by the communities by means of mingas. Additionally, the heterogenic distances and complicated topography play a role against certain communities, as they generate inequities for the Access and mobility of products and materials that have impact in the capacity to satisfy their basic needs.

Approximately half of the production is concentrated in potatoes, corn, chochos, and lima beans, and the rest is distributed among a variety of products with marginal volumes. In this scenario, profitability is captured by the intermediary who assumes no risks, since commercialization occurs at the Guamote fair, where the farmer arrives after a long work period of planting, care, harvesting, and transportation, which is affected by conditions outside his control.

\section{INTRODUCCIÓN}

La idea de trabajar en este cantón surge a partir de la revisión documental y en territorio de una población muy empobrecida, carente de servicios básicos, que se ubica en un lugar apropiado para la conservación, pero con tradición productiva agrícola, donde organizaciones privadas y públicas in- 
tervienen y pese a estos esfuerzos, se mantienen las mismas condiciones de pobreza durante el paso del tiempo. El diagnóstico más relevante para cumplir el objetivo de esta investigación es el análisis de la estructura de la comercialización existente, el comportamiento de la oferta de la papa, maíz suave choclo, haba tierna y cebada, que se determinó son los principales productos del cantón, los niveles de rentabilidad de los agricultores e intermediarios y los sistemas de transporte, financiero público y privado.

Es un territorio poblado mayoritariamente por indígenas de las estribaciones orientales de la cordillera cuyas actividades productivas no son influyentes en la economía del país, aunque su ubicación geográfica une estratégicamente la serranía con la cuenca amazónica (Diario los Andes, 2011). Su producción se destina para el autoconsumo y el comercio que se realiza de forma centralizada en las dos ferias locales: Guamote (Matriz) los jueves y Cebadas los sábados, para posteriormente dirigirse a los mercados mayoristas de Riobamba y Guayaquil (Parlamento indígena, 2001). Los agricultores asumen los costos de producción entre los que se incluye el traslado de sus productos a las ferias para su comercialización, donde negocian sus productos a los precios de mercado con ingresos escasos que no garantizan ni- veles de rentabilidad que les permitan cubrir sus necesidades básicas; en este contexto, cobra importancia la intermediación que forma parte de la cadena de comercialización de la producción agrícola cantonal. El principal inconveniente de los campesinos está en los escasos rendimientos de productos sumados a la variabilidad de precios que reciben de los intermediarios.

Se puede identificar el cambio de una economía de subsistencia y relaciones de reciprocidad a una orientada al mercado en donde priman relaciones comerciales como se muestra en la feria de Guamote; otra consecuencia de este cambio es el progresivo abandono del campo y que la agricultura ya no se la considere como una actividad productiva rentable y de progreso; adicionalmente, se da el aparecimiento de trabajo informal con más de un empleo (migración temporal) y aparece el trabajo infantil y adolescente (Parlamento indígena, 2001). Se presenta una redefinición de los imaginarios internos de las comunidades donde se difumina la solidaridad, se desestructura la idea de comunidad y cultura tradicionales. Esta ruptura de las formas de organización colectiva significa el aparecimiento de un proceso de individualización donde el indígena explota al mismo indígena transformándose en un nuevo tipo de terrateniente o en intermediario. 
Revista PUCE. ISSN 1390-7719. Núm.103. 3 de mayo de 2016 -

3 De noviembre de 2016. Alfredo Altamirano UlLoa,

Mayra Beltrán Morales. PP. 185-231

En cuanto a la infraestructura que apoya a la producción y comercialización cantonal, Guamote está atravesado por la carretera panamericana, de esta se desprenden accesos mayoritariamente de cuarto orden a las 124 comunidades, es decir de tierra, sin alcantarillas ni cunetas, con radios de curvatura inapropiados, con pendientes pronunciadas debido a una topografía irregular montañosa (parlamento indígena, 2001), lo que demuestra que prima la vialidad nacional y urbana en desmedro de la rural (Diario los Andes, 2011).

Para el desarrollo de las actividades productivas, el financiamiento es un medio que viabiliza el crecimiento, sobre todo cuando los actores se encuentran debajo de la línea de pobreza como es la realidad del cantón Guamote; en este contexto, el sector de servicios financieros y sus políticas crediticias en apoyo a la producción son insuficientes y con requisitos altos que no pueden cumplir por la mayoría de la población guamoteña, por lo que en algunos casos dependen del crédito informal que se lo conoce como "chulco", lo que pone en riesgo su patrimonio y sumergiéndose aún más en la pobreza.

Este trabajo se desarrolla desde la perspectiva teórica del Desarrollo Económico, noción que nació como un subproducto del orden establecido después de la segunda guerra mundial, ordenamiento cuestionado por el aparecimiento de sucesivas crisis y falta de respuesta a la satisfacción de necesidades de las poblaciones especialmente del llamado tercer mundo, en donde surgen planteamientos alternativos, entre ellos una ideología de lo pequeño con identidad local que descubre que la única posibilidad de supervivencia es impulsar procesos de desarrollo localmente controlados, mediante iniciativas de creación de pequeñas empresas, impulso de proyectos innovadores y la dinamización de tejidos socioeconómicos locales (Arocena, 2002).

El Desarrollo Económico Local se entiende como un proceso de crecimiento y cambio estructural de la economía e identifica tres dimensiones: una económica caracterizada por un sistema de producción donde se busca usar eficientemente los factores productivos, generar economías de escala y aumentar la productividad que mejora la competitividad en los mercados; otra sociocultural, que se fundamenta en relaciones económicas y sociales asentadas en valores que sirven de base al proceso de desarrollo con la intervención de instituciones locales; y otra político-administrativa, con roles ejecutores o rectores de la política pública que favorecen a la producción e impulsan el desarrollo sostenible (Vázquez, 2000). 
Las relaciones entre los grupos son de naturaleza local, en los cuales la riqueza que se genera requiere controles en aspectos técnico-productivos y comerciales, con una sociedad que se nutra de su propia historia con un sistema de valores que se interioriza en cada uno de sus miembros con identidad colectiva. Para ello es necesario que el conjunto humano que vive en un territorio comparta rasgos comunes, en otras palabras, los individuos constituyen una sociedad local cuando muestran una manera de ser determinada, donde el tamaño del territorio y el número de habitantes no es significativo (Arocena, 2002).

Desde esta perspectiva teórica, se realiza el diagnóstico socioeconómico y físico del cantón Guamote que evidencia, que el desarrollo no llega todavía a la población, puesto que el sistema de producción es precario, con explotación extensiva de los recursos naturales que sacrifica la sostenibilidad de los mismos, con niveles de producción y rendimientos bajos en comparación a los óptimos y con participación mínima en los mercados. En relación con lo sociocultural, se presentan relaciones comerciales con intermediarios, un traspaso de la propiedad de la tierra de manos mestizas a indígenas bajo la premisa de que ser propietario de la tierra les ayudará a salir de la pobreza; además se apoya con una fuerte intervención de organismos nacionales e internacionales que tratan de mejorar las precarias condiciones de vida de las comunidades. En el aspecto político-administrativo, se consolida el liderazgo indígena en puestos de poder local y provincial con miras a impulsar el desarrollo sostenible.

Asimismo, no se puede analizar un proceso de desarrollo local sin referirlo a la sociedad global en la cual está inmerso, por lo que se deben señalar los elementos que constituyen los mínimos necesarios que permitan hablar de sociedad local, puesto que no toda subdivisión de un territorio es una sociedad local; por lo tanto, para aplicar este término, se debe reunir condiciones en dos niveles fundamentales, que son: el socioeconómico y cultural (Arocena, 2002). En aplicación al concepto expuesto para esta investigación, se entiende como local al territorio político administrativo que constituye el cantón Guamote y a sus tres parroquias que son Guamote Matriz, Cebadas y Palmira; además, la provincia con sus indicadores socioeconómicos, productivos, comerciales y de recursos naturales, sumados al marco regulador que establece el Gobierno Nacional y Provincial, son los principales elementos analizados que se constituyen como parte de una sociedad global en la que están inmersos.

Otra característica del desarrollo económico local es la elegibilidad de la 
Revista PUCE, ISSN 1390-7719. Núm.103. 3 de mayo de 2016 -

3 De noviembre de 2016. Alfredo Altamirano UlLoa,

Mayra Beltrán Morales. PP. 185-231

localización de las actividades productivas, en función de la distancia entre el mercado y las comunidades productoras; allí se incorpora el sector de transporte que tiene impacto en los costos. Todo esto se debe complementar con la diversidad de productos, demanda, lugar de comercialización y economías de escala (Tello, 2006). Esta teoría se refiere a procesos de acumulación de capital en regiones concretas (Vázquez, 2000); para este caso, los procesos de acumulación se concentran en pocas personas dueñas de la tierra en grandes extensiones y dueños del capital y medios de trasporte relacionados con el proceso de comercialización, que se da principalmente en la única feria cantonal reconocida a nivel provincial y desde allí se extiende a los mercados mayoristas de Riobamba y Guayaquil por acción de la intermediación.

Se trata de procesos de desarrollo económicos que se caracterizan por la organización sistémica de las unidades de producción articuladas en la tradición local, con disponibilidad de mano de obra barata, una cultura atenta a las innovaciones, que favorecen la acumulación de capital en empresas competitivas en mercados nacionales e internacionales (Vázquez, 2000). El sistema de producción de las comunidades de Guamote se estructura en función de su tradición agrícola y de recursos hu- manos limitados por escasos niveles de escolaridad, que se resisten a la innovación y cambio, por lo que se resigna a seguir siendo agricultores de pequeña escala, cuyos excedentes se comercializan localmente en la feria para la reventa y el consumo, lo que demuestra que en el cantón no se da paso al desarrollo de empresas locales competitivas en el mercado provincial, menos aún a nivel nacional e internacional.

La organización del sistema productivo local forma redes de empresas, propicia la generación de economías de escala y la reducción de los costos de transacción y por lo tanto rendimientos crecientes y crecimiento económico. Igualmente, el supuesto básico de esta teoría es que las localidades y territorios tienen un conjunto de recursos no explotados que constituyen su potencial de desarrollo cuya utilización conduce a la mejora del bienestar de la población (Vázquez, 2000). Los grupos económicos privados son agentes de un área local que a través de su actividad inciden en la economía en función de sus intereses y no del interés público o social.

Hirschman pensaba que la principal escasez con que se enfrenta la mayoría de los países en vías de desarrollo no es de capital o de otros recursos, sino la capacidad para adoptar decisiones de inversión eficientes, su estrategia de desarrollo económico recomendaba a 
los gobiernos que la principal prioridad de su política económica esté en el estímulo a las inversiones que fueran capaces de inducir un mayor volumen de decisiones de inversión asociadas con las primeras (Espina, 1994). Así, la existencia de eslabonamientos hacia adelante y hacia atrás, la creación de nuevas empresas, el aprovechamiento de recursos, la construcción de infraestructura pública, pueden generar círculos virtuosos de crecimiento (Tello, 2006).

El tipo de investigación de este trabajo fue exploratorio puesto que no existen trabajos previos con enfoque comercial en el cantón; como método de investigación en el ámbito empírico se realizó trabajo de campo en la feria de Guamote para el levantamiento de información de costos, niveles de producción, unidades de medida, precios de venta al consumidor final y a intermediarios, utilizando encuestas para cada uno de los principales productos agrícolas. Durante las visitas al cantón, se utilizó la observación de la dinámica comercial en la Feria de Guamote y la de Cebadas; esta última se desenvuelve en condiciones aún más precarias.

Adicionalmente se utilizó información secundaria procedente de bases de datos de los censos de población y vivienda 2001 y 2010, censo económico 2010, censo agrícola del año 2000, estadísticas de transporte del INEC, con- sulta de precios diaria de cada producto durante el período 2011-2012, agenda de competitividad de la provincia de Chimborazo 2010, la línea base referencial del GAD Guamote 2011, línea base referencial del MAGAP, el SIISE 6.1, entre las más relevantes. Vale la pena resaltar que se procesó estadísticamente la información selecta de cada tema. Para lograr un equilibrio en el análisis, se compararon datos levantados por INEC con igual metodología en el período intercensal 2001-2010, con el propósito de comprender la evolución de la situación socioeconómica. Se utilizó una variedad de libros y documentos publicados por una diversidad de entidades públicas y privadas cuyo detalle consta en la bibliografía.

Dentro de la investigación, se identificaron varios niveles de análisis entre ellos la realidad socioeconómica de la población y del medio físico en el cual están inmersos; las características de los agricultores, sus niveles de producción, comercialización y rentabilidad, influencia de la intermediación, el sistema de transporte, sistema financiero, factores geográficos de tenencia y uso del suelo; todo esto permitió elaborar conclusiones y recomendaciones que condujeron a proponer un nuevo modelo de gestión comercial que busque mejores condiciones de vida para la mayoría de la población. 
Revista PUCE, ISSN 1390-7719. Núm.103. 3 de MAYO de 2016 -

3 De noviembre de 2016. Alfredo Altamirano UlLoA,

Mayra BELtrán MORALES. PP, 185-231

\section{PRODUCCIÓN Y COMERCIALIZACIÓN}

\section{Producción}

Las prácticas productivas de los campesinos e indígenas en las comunidades y áreas rurales son sencillas y se sustentan en la labor de arado y la tracción a través de yunta, conocimientos que son transferidos entre generaciones por la tradición oral, que se fundamenta entre otras cosas en que las comunidades se encuentran en cierto aislamiento geográfico y con vías de acceso deficientes, lo que afecta a la productividad de sus cultivos. Para contextualizar el análisis de la actividad comercial y su rentabilidad, es necesario partir de la observación de la variación de las superficies destinadas a los cultivos y pastos entre los años 2000 y 2011.

TABLA 1

EVOLUCIÓN DE SUPERFICIES DE CULTIVOS 20002011

\begin{tabular}{|l|c|c|}
\hline \multicolumn{1}{|c|}{ V A R IA B LE } & $\begin{array}{c}\text { C A N T Ó N } \\
\text { G UA M O T E }\end{array}$ & \multirow{2}{*}{ A ÑOS } \\
\hline \begin{tabular}{l|c|} 
Superficie destinada para los cultivos \\
(Ha)
\end{tabular} & $18.028,0$ & \multirow{2}{*}{2000} \\
\cline { 1 - 2 } $\begin{array}{l}\text { Superficie destinada para pastos } \\
\text { cultivados (Ha) }\end{array}$ & $14.450,0$ & \\
\hline Superficie sembrada por cultivos (Ha) & $3.751,0$ & \multirow{2}{*}{2011} \\
\hline $\begin{array}{l}\text { Superficie de pastos naturales y } \\
\text { cultivados (Ha) }\end{array}$ & $2.977,0$ & \\
\hline
\end{tabular}

Fuente: Base de datos de la Agenda de Competitividad-2011 (documento borrador)

Elaborado por: Mayra Beltrán Morales, Alfredo Altamirano Ulloa

De manera referencial, se aprecia en la tabla 1 una reducción de 79,19\% hectáreas dedicada a cultivos y un 79,39\% de pastos'; este abandono de tierras podría deberse a la mala calidad del suelo, escasez de agua, a la baja productividad y rentabilidad de los cultivos, que guarda relación con la extensión de las parcelas que se encontraban entre 2,1 y 3,5 hectáreas por UPA, frente a la superficie promedio familiar de $1 \mathrm{Ha}$ en Guamote Matriz y 2 en las parroquias Palmira y Cebadas registras en la base de datos de línea base del año 2011 del cantón (GAD GUAMOTE, 2011), lo que muestra que el proceso de fragmentación de la tierra avanza en detrimento de la rentabilidad que sostienen a los agricultores en condiciones de pobreza extrema.

1 Los datos registrados en la Base de Datos de la Agenda de Competitividad 2011 del cantón Guamote, provienen de dos fuentes, la del año 2000 corresponde al Censo Agrícola y la del 2011 a la información levantada por la Dirección Provincial del MAGAP, esto explica por qué la afirmación hecha es únicamente referencial al no existir igualdad de criterios para levantar y procesar la información, y es la única información disponible. 
LA ESTRUCTURA DE LA COMERCIALIZACIÓN, FINANCIAMIENTO

$Y$ TRANSPORTE DE LOS PRINCIPALES PRODUCTOS AGRÍCOLAS Y

SU RENTABILIDAD PARA LOS AGRICULTORES DEL CANTÓN GUAMOTE

TABLA 2

SUPERFICIE DE CULTIVO DE GUAMOTE EN RELACIÓN CON LA PROVINCIA DE CHIMBORAZO 2011

\begin{tabular}{|l|c|c|c|c|}
\hline \multicolumn{1}{|c|}{ C UL T IV O } & $\begin{array}{c}\text { G UA M O T E } \\
\text { (H a ) }\end{array}$ & $\begin{array}{c}\text { P O R C E N T A J E } \\
\text { C A N T O N A L }\end{array}$ & $\begin{array}{c}\text { C H IM B O R A Z O } \\
\text { (H a ) }\end{array}$ & $\begin{array}{c}\text { P O R C E N T A J E } \\
\text { P R O V IN C IA L }\end{array}$ \\
\hline Haba tierna & 736,0 & $20,0 \%$ & $3.027,5$ & $24,0 \%$ \\
\hline Papa & $1.712,0$ & $46,0 \%$ & $7.681,1$ & $22,0 \%$ \\
\hline Cebada & 805,0 & $21,0 \%$ & $4.412,8$ & $18,0 \%$ \\
\hline Brócoli & 16,0 & $0,0 \%$ & 172,0 & $9,0 \%$ \\
\hline Maíz suabe choclo & 320,0 & $9,0 \%$ & $4.551,1$ & $7,0 \%$ \\
\hline Cebolla colorada & 10,0 & $0,0 \%$ & 173,6 & $6,0 \%$ \\
\hline Quinoa & 10,0 & $0,0 \%$ & 385,9 & $3,0 \%$ \\
\hline Trigo & 10,0 & $0,0 \%$ & $1.329,0$ & $1,0 \%$ \\
\hline Arbeja tierna & 10,0 & $0,0 \%$ & $1.402,7$ & $1,0 \%$ \\
\hline Fréjol tierno & & & $1.835,9$ & $0,0 \%$ \\
\hline Cebolla blanca & & & 549,0 & $0,0 \%$ \\
\hline Tomate riñón & & & 282,2 & $0,0 \%$ \\
\hline Otros & 122,0 & $3,0 \%$ & & \\
\hline \multicolumn{1}{|c|}{ TOTAL } & $3.751,0$ & & $25.802,8$ & \\
\hline
\end{tabular}

Fuente: Base de datos de la Agenda de Competitividad -2011(documento borrador)

Elaborado por: Mayra Beltrán Morales, Alfredo Altamirano Ulloa

Para complementar lo descrito en el párrafo anterior, se observa en la tabla 2 que los principales productos de acuerdo con la extensión de cultivo en el año 2011 en Guamote son papa, cebada, haba tierna y maíz suave choclo que representan el $96 \%$ de la producción cantonal. Además, estos mismos productos tienen una incidencia en la producción provincial, en la cual el primer lugar ocupa el haba tierna con aproximadamente la cuarta parte, seguida de la papa y cebada con la quinta parte y finalmente el maíz suave que aporta la décima parte de la producción provincial. Esto muestra que la actividad agrícola de Guamote se mantiene concentrada en cuatro productos; en el caso de la papa representa valores significativos para la provincia frente a los otros nueve cantones restantes. 
ReVista PUCE. ISSN 1390-7719. Núm.103. 3 de mayo de 2016 -

3 De noviembre de 2016. Alfredo Altamirano UlLoa, Mayra Beltrán MORALES. PP. $185-231$

TABLA 3

SUPERFICIE Y PRODUCCCIÓN DE CULTIVO DE LOS PRINCIPALES PRODUCTOS DE GUAMOTE A NIVEL PARROQUIAL 2011

\begin{tabular}{|c|c|c|c|c|c|c|c|c|c|}
\hline \multirow{3}{*}{ PRODUCTO } & \multicolumn{9}{|c|}{ PARROQUIA } \\
\hline & \multicolumn{3}{|c|}{ GUAMOTE } & \multicolumn{3}{|c|}{ CEBADAS } & \multicolumn{3}{|c|}{ PALMIR A } \\
\hline & $\begin{array}{c}\text { SUPERFIC IE } \\
\text { SEMBRADA } \\
(H a)\end{array}$ & $\begin{array}{c}\text { PR ODUC C IÓN } \\
\text { (libras) }\end{array}$ & $\begin{array}{c}\text { PROD UC C IÓN } \\
\text { (TM) }\end{array}$ & $\begin{array}{c}\text { SUPERFICIE } \\
\text { SEMBRADA } \\
\text { (Ha) }\end{array}$ & $\begin{array}{c}\text { P R ODUC C IÓN } \\
\text { (libras) }\end{array}$ & $\begin{array}{l}\text { PRODUCC IÓN } \\
\text { (TM) }\end{array}$ & $\begin{array}{c}\text { SUPERFICIE } \\
\text { SEMBRADA } \\
\text { (Ha) }\end{array}$ & $\begin{array}{c}\text { PR ODUC C Ć́N } \\
\text { (libras) }\end{array}$ & $\begin{array}{l}\text { PRODUC CIÓN } \\
\text { (TM) }\end{array}$ \\
\hline ARBEJA TIERNA EN VAINA & 10,0 & 80,0 & 55,0 & & & & & & \\
\hline CEBADA & 155,0 & $1.000,0$ & 211,0 & 125,0 & 600,0 & 170,0 & 525,0 & $1.200,0$ & 716,0 \\
\hline CEBOLLA COLORADA & 10,0 & 90,0 & 41,0 & & & & & & \\
\hline CHOCLO & & & & & & & 80,0 & 100,0 & 44,0 \\
\hline HABA TIERNA EN VAINA & 218,0 & 560,0 & 347,0 & 188,0 & 350,0 & 325,0 & 330,0 & 840,0 & 544,0 \\
\hline MAZZ SUAVE CHOCLO & 10,0 & 80,0 & 33,0 & 310,0 & 800,0 & $1.015,0$ & & & \\
\hline MELLOCO & & & & & & & 10,0 & 80,0 & 33,0 \\
\hline OCA & & & & 28,0 & 165,0 & 90,0 & & & \\
\hline PAPA & 560,0 & $1.200,0$ & $5.091,0$ & 637,0 & $1.220,0$ & $6.591,0$ & 515,0 & 960,0 & $4.807,0$ \\
\hline TRIGO & 10,0 & 100,0 & 11,0 & 270,0 & & & & & \\
\hline ZANAHORIA AMARILLA & 20,0 & 70,0 & 64,0 & & & & & & \\
\hline QUINUA & & & & 10,0 & 100,0 & & & & \\
\hline TOTAL & 993,0 & $3.180,0$ & $5.853,0$ & $1.568,0$ & $3.235,0$ & $8.191,0$ & $1.460,0$ & $3.180,0$ & $6.144,0$ \\
\hline
\end{tabular}

Fuente: Base de datos de la Agenda de Competitividad (documento borrador)

Elaborado por: Mayra Beltrán Morales, Alfredo Altamirano Ulloa

Asimismo, la producción en toneladas métricas expuestas en la tabla 3, evidencia como principal producto la papa en las tres parroquias que alcanzó en el año 2011 una producción total referencial de 16.489 toneladas métricas con un promedio aproximado de $5.496 \mathrm{Tm}$., por parroquia; en segundo lugar de importancia está el haba tierna en vaina con 1.216 Tm. y un promedio aproximado de $405 \mathrm{Tm}$.; el tercer lugar es para la cebada con una producción de 1.097 Tm., mayoritariamente producida en Palmira; en cuarto lugar el maíz suave choclo con un total de 1.048 Tm., producidas casi exclusivamente en la parroquia Cebadas (GAD Guamote, 2011).

TABLA 4

DISTRIBUCIÓN Y USO PORCENTUAL DE LA PRODUCCION DEL CANTÓN GUAMOTE AÑO 2011

\begin{tabular}{|l|c|c|c|c|c|}
\hline \multirow{2}{*}{ P R o D UC T O } & \multicolumn{3}{|c|}{ M A G A P - 2011 } & G UA M O T E L ́ N E A B A S E 20 11 \\
\cline { 2 - 6 } & S E M IL L A & C O N S UM o & VE N T A & C O N S U M O & VE N T A \\
\hline P apa & $10,0 \%$ & $10,0 \%$ & $80,0 \%$ & $25,5 \%$ & $74,5 \%$ \\
\hline Zanahoria & $10,0 \%$ & $10,0 \%$ & $80,0 \%$ & $53,2 \%$ & $46,8 \%$ \\
\hline Alverja & $10,0 \%$ & $10,0 \%$ & $80,0 \%$ & $4,0 \%$ & $96,0 \%$ \\
\hline Cebolla paiteña & $10,0 \%$ & $10,0 \%$ & $80,0 \%$ & $59,0 \%$ & $41,0 \%$ \\
\hline Maíz & $10,0 \%$ & $10,0 \%$ & $80,0 \%$ & $97,0 \%$ & $2,8 \%$ \\
\hline Trigo & $10,0 \%$ & $10,0 \%$ & $80,0 \%$ & $45,1 \%$ & $54,9 \%$ \\
\hline Habas & $10,0 \%$ & $10,0 \%$ & $80,0 \%$ & $20,2 \%$ & $79,8 \%$ \\
\hline C aebada & $10,0 \%$ & $10,0 \%$ & $80,0 \%$ & $49,7 \%$ & $50,3 \%$ \\
\hline Cebolla & $10,0 \%$ & $10,0 \%$ & $80,0 \%$ & $59,0 \%$ & $41,0 \%$ \\
\hline Chocho & $10,0 \%$ & $10,0 \%$ & $80,0 \%$ & $16,9 \%$ & $83,1 \%$ \\
\hline Melloco & $10,0 \%$ & $10,0 \%$ & $80,0 \%$ & $77,4 \%$ & $22,6 \%$ \\
\hline Oca & $10,0 \%$ & $10,0 \%$ & $80,0 \%$ & $78,4 \%$ & $21,6 \%$ \\
\hline
\end{tabular}

Fuente: SINAGAP MAGAP- Línea Base Referencial - GAD GUAMOTE- Encuesta de Línea Base Elaborado por: Mayra Beltrán Morales, Alfredo Altamirano Ulloa 
LA ESTRUCTURA DE LA COMERCIALIZACIÓN, FINANCIAMIENTO

Y TRANSPORTE DE LOS PRINCIPALES PRODUCTOS AGRÍCOLAS Y

SU RENTABILIDAD PARA LOS AGRICULTORES DEL CANTÓN GUAMOTE

En la tabla 4 se refleja que los cultivos sirven para garantizar en alguna manera la subsistencia familiar, mantener la generación de semillas, devolver lo prestado y la venta al mercado (SINAGAP MAGAP, 2010); como se puede apreciar en las primeras tres columnas de la tabla (información de campo levantada por el MAGAP), el 20\% se dedica a semilla y autoconsumo, mientras que un $80 \%$ de producto sale a la venta; esta información es homogénea para todos los productos analizados, mientras que en la información levantada por el GAD, en Guamote aparecen porcentajes heterogéneos donde cobran relevancia la venta de arveja, habas y papa en ese orden; llama la atención que el maíz que se produce se dedica casi en su totalidad al autoconsumo, seguido de cerca de la mitad de la producción de cebolla paiteña, zanahoria, cebada y trigo.

Resaltan la utilización para su consumo del maíz con un 97,2\%, la oca con $78,4 \%$ y el melloco con $77,4 \%$; estos productos alcanzaron en 2001 bajos porcentajes de producción como se registra en la tabla 4 . En contraste se aprecia que los productos analizados en este trabajo de investigación se venden mucho más de lo que se consumen, es así que el haba se comercializa en un $79,8 \%$, seguido de la papa con el 74,5\% y la cebada con 50,3\%; estos tres productos representan en su conjunto para el año 2001 un 61,68\% y para el año 2011 un 56,65\% de la producción, lo que revela que el comercio del cantón es dinámico y dependiente de los mismos productos.

En la tabla 5 se detallan las preferencias que cada parroquia tiene en las diferentes variedades de producto, así tenemos que para el caso de la papa las variedades Gabriela y Chola se producen en todo el cantón, a diferencia de la Chaucha, Cecilia, Fripapa y Superchola. En cuanto a la cebada la parroquia Palmira siembra todas las variedades, mientras que la preferida por los agricultores a nivel cantonal es la Franciscana; en el haba tierna en vaina la variedad Huigra es la que se siembra en todo el cantón y para el caso de maíz choclo suave se siembra la variedad Blanco casi exclusivamente en Cebadas y esto tiene relación con el autoconsumo de los agricultores de este producto reflejado en la tabla 4 (GAD Guamote, 2011). 
ReVista PUCE. ISSN 1390-7719. Núm.103. 3 de mayo de 2016 -

3 De noviembre de 2016. Alfredo Altamirano UlLoa,

Mayra Beltrán MORALES. PP. $185-231$

TABLA 5

PRODUCCIÓN PARROQUIAL DE LOS PRINCIPALES

PRODUCTOS DEL CANTÓN POR VARIEDAD AÑO 2011

\begin{tabular}{|c|c|c|c|c|c|}
\hline \multirow{2}{*}{ PRODUCTO } & \multicolumn{3}{|c|}{ PRODUCCIÓN ENTM } & \multirow{2}{*}{$\begin{array}{l}\text { TOTAL } \\
\text { GENERAL }\end{array}$} & \multirow{2}{*}{$\begin{array}{c}\text { PORCENTAJE } \\
\text { POR } \\
\text { PRODUCTO }\end{array}$} \\
\hline & CEBADAS & GUAMOTE & P ALMIR A & & \\
\hline PAPA & 6.591 & 5.091 & 4.807 & 16.489 & $100,0 \%$ \\
\hline Gabriela & 2.311 & 2.909 & 3.398 & 8.618 & $52,0 \%$ \\
\hline Chola & 3.385 & 273 & 500 & 4.158 & $25,0 \%$ \\
\hline Chaucha & 895 & 455 & & 1350 & $8,0 \%$ \\
\hline Cecilia & & 1.091 & & 1091 & $7,0 \%$ \\
\hline Fripapa & & & 909 & 909 & $6,0 \%$ \\
\hline Superchola & & 364 & & 364 & $2,0 \%$ \\
\hline CEBADA & 170 & 211 & 716 & 1.097 & $100,0 \%$ \\
\hline Malta & & 75 & 484 & 559 & $51,0 \%$ \\
\hline Franciscana & 170 & 109 & 109 & 388 & $35,0 \%$ \\
\hline Shyri & & 27 & 82 & 109 & $10,0 \%$ \\
\hline Cañicapa & & & 41 & 41 & $4,0 \%$ \\
\hline $\begin{array}{l}\text { HABA TIERNA } \\
\text { EN VAINA }\end{array}$ & 325 & 347 & 544 & 1.216 & $100,0 \%$ \\
\hline \begin{tabular}{|l} 
Huigra \\
\end{tabular} & 325 & 283 & 433 & 1.041 & $86,0 \%$ \\
\hline semiverde & & 32 & 111 & 143 & $12,0 \%$ \\
\hline Común & & 32 & & 32 & $3,0 \%$ \\
\hline $\begin{array}{l}\text { MAÍZ S UAVE } \\
\text { CHOCLO }\end{array}$ & 1.015 & 33 & & 1.048 & $100,0 \%$ \\
\hline Blanco & 1.015 & 33 & & 1.048 & $100,0 \%$ \\
\hline $\begin{array}{c}\text { TOTAL } \\
\text { GENERAL }\end{array}$ & 8.101 & 5.682 & 6.067 & 19.850 & \\
\hline
\end{tabular}

Fuente: Línea Base Referencial Guamote, 2011. SINAGAP-MAGAP

Elaborado por: Mayra Beltrán Morales, Alfredo Altamirano Ulloa

\section{Comercialización}

En la provincia de Chimborazo, se identifican 43 centros de comercialización distribuidos en los diez cantones, de los cuales la mayor parte se ubican en Riobamba, Pallatanga y Guamote, lo que demuestra la alta concentración de la comercialización con un $68 \%$ de centros de acopio en apenas tres cantones como se ve en la tabla 6, del cual el 19\% se encuentra en Guamote, a pesar de las condiciones socioeconómicas extremas del cantón (Gobierno Autónomo Descentralizado de la Provincia de Chimborazo, 2011), lo que podría revelar su importancia comercial y un aporte a la dinámica productiva de la provincia. El $30 \%$ de centros de acopio se encuentran en la ciudad de Riobamba entre los cuales se destaca el Mercado Mayorista, que por su condición de mayorista es el principal lugar de comercialización de la producción agrícola de los cantones y provincias vecinas, al cual se dirige una buena parte de la producción guamoteña.

Otra característica de la estructura de comercialización del cantón Guamote es su informalidad, pues al contrastar los datos de la información oficial registrada en la Superintendencia de Compañías con la del Censo Económico, se evidencia que en Guamote, existen 2 compañías formalmente registradas de un total de 524 de la provincia. Además, contrasta el 3\% de establecimientos económicos guamoteños que se dedican a la actividad de comercio frente a un 78\% del registro del cantón Riobamba detallados en la tabla 5 (INEC, 2010). 
LA ESTRUCTURA DE LA COMERCIALIZACIÓN, FINANCIAMIENTO

Y TRANSPORTE DE LOS PRINCIPALES PRODUCTOS AGRÍCOLAS Y

SU RENTABILIDAD PARA LOS AGRICULTORES DEL CANTÓN GUAMOTE

TABLA 6

CENTROS DE COMERCIALIZACIÓN DE CHIMBORAZO POR CANTONES 2011

\begin{tabular}{|c|c|c|c|c|c|c|c|c|c|c|}
\hline \multirow{2}{*}{ CANTÓN } & \multicolumn{2}{|c|}{$\begin{array}{c}\text { CENTROS } \\
\text { COMERCIALIZACIÓN } \\
\end{array}$} & \multicolumn{2}{|c|}{ COMPANIAS * } & \multicolumn{2}{|c|}{$\begin{array}{l}\text { ESTABLECIMIENTOS } \\
\text { ECONOMICOS }\end{array}$} & \multicolumn{2}{|c|}{$\begin{array}{l}\text { PERSONAL OC UPADO EN } \\
\text { ESTABLECIMIENTOS } \\
\text { ECONOMICOS *** }\end{array}$} & \multicolumn{2}{|c|}{$\begin{array}{c}\text { ACTIVIDAD } \\
\text { ECONOMICA COMERCIO }\end{array}$} \\
\hline & CANTIDAD & $\begin{array}{l}\text { PORCENTAJE } \\
\text { PROVINCIAL } \\
\end{array}$ & CANTIDAD & $\begin{array}{l}\text { PORCENTAJE } \\
\text { PROVINCIAL }\end{array}$ & CANTIDAD & $\begin{array}{l}\text { PORCENTAJE } \\
\text { PROVINCIAL }\end{array}$ & CANTIDAD & \begin{tabular}{|l} 
PORCENTALE \\
PROVINCIAL \\
\end{tabular} & CANTIDAD & $\begin{array}{l}\text { PORCENTAJE } \\
\text { PROVINCIAL }\end{array}$ \\
\hline GUANO & 1 & $2,0 \%$ & 11 & $2,0 \%$ & 559 & $3,0 \%$ & 1.757 & $3,0 \%$ & 254 & $3,0 \%$ \\
\hline PENIPE & 1 & $2,0 \%$ & 3 & $1,0 \%$ & 103 & $1,0 \%$ & 637 & $1,0 \%$ & 29 & $0,0 \%$ \\
\hline CHAMBO & 1 & $2,0 \%$ & 7 & $1,0 \%$ & 514 & $3,0 \%$ & 1.410 & $3,0 \%$ & 189 & $2,0 \%$ \\
\hline COLTA & 3 & $7,0 \%$ & 3 & $1,0 \%$ & 341 & $2,0 \%$ & 776 & $2,0 \%$ & 154 & $2,0 \%$ \\
\hline PALLATANGA & 8 & $19,0 \%$ & 3 & $1,0 \%$ & 297 & $2,0 \%$ & 730 & $1,0 \%$ & 154 & $2,0 \%$ \\
\hline CUMANDÁ & 4 & $9,0 \%$ & 2 & $0,0 \%$ & 483 & $3,0 \%$ & 1.262 & $2,0 \%$ & 256 & $3,0 \%$ \\
\hline CHUNCHI & 2 & $5,0 \%$ & 5 & $1,0 \%$ & 441 & $3,0 \%$ & 973 & $2,0 \%$ & 229 & $3,0 \%$ \\
\hline ALAUSI & 2 & $5,0 \%$ & 9 & $2,0 \%$ & 618 & $4,0 \%$ & 1.604 & $3,0 \%$ & 297 & $4,0 \%$ \\
\hline GUAMOTE & 8 & $19,0 \%$ & 2 & $0,0 \%$ & 442 & $3,0 \%$ & 1.088 & $2,0 \%$ & 225 & $3,0 \%$ \\
\hline RIOBAMBA & 13 & $30,0 \%$ & 479 & $91,0 \%$ & 12272 & $76,0 \%$ & 41.122 & $80,0 \%$ & 6.276 & $78,0 \%$ \\
\hline PROVINCIA & 43 & $100,0 \%$ & 524 & $100,0 \%$ & 16070 & $100,0 \%$ & 51359 & $99,0 \%$ & 8063 & $100,0 \%$ \\
\hline
\end{tabular}

Fuente: * Agenda de Competitividad 2010

** Superintendencia de Compañías 2011

*** Censo Económico 2010

Elaborado por: Mayra Beltrán Morales, Alfredo Altamirano Ulloa

Comportamiento de la oferta de los principales productos cantonales

\section{Oferta de papa}

En el caso de la papa, existen en el país muchas variedades pues constituye un tubérculo importante en la alimentación de la mayoría de la población, especialmente en la sierra ecuatoriana. En el cantón Guamote se identifican las variedades más sembradas a nivel parroquial que son Gabriela con un total de 8.619 Tm, le sigue Chola con $4.158 \mathrm{Tm}$, luego la Chaucha que se siembra en las parroquias Guamote y Palmira con 1.349 Tm y en cuarto lugar la Cecilia con $1.091 \mathrm{Tm}$ producidas exclusivamente en la parroquia Guamote Matriz, información que se desagrega en la tabla 7. El 74,5\% de la producción se destina a la venta como se citó en la tabla 4, lo que revela la importancia de este producto como fuente de ingreso de las comunidades de las tres parroquias del cantón.

TABLA 7

PRODUCCIÓN DE PAPA EN GUAMOTE AÑO 2011

\begin{tabular}{|c|c|c|c|c|}
\hline \multicolumn{5}{|c|}{ PRODUCCIÓN ENTM } \\
\hline $\begin{array}{c}\text { PRODUCTOS } \\
\text { POR } \\
\text { VARIEDAD }\end{array}$ & GUAMOTE & CEBADAS & PALMIRA & $\begin{array}{l}\text { LUGAR DE } \\
\text { VENTA }\end{array}$ \\
\hline Cecilia & 1.091 & & & \multirow{7}{*}{ 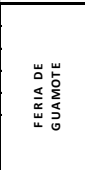 } \\
\hline Chaucha & 455 & 895 & & \\
\hline \begin{tabular}{|l|} 
Chola \\
\end{tabular} & 273 & 3.385 & 500 & \\
\hline Gabriela & 2.909 & 2.311 & 3.398 & \\
\hline Superchola & 364 & & & \\
\hline Fripapa & & & 909 & \\
\hline TOTALDE & 5.091 & 6.591 & 4.807 & \\
\hline
\end{tabular}

Fuente: SINAGAP-MAGAP 2011

Elaborado por: Mayra Beltrán Morales, Alfredo Altamirano Ulloa 
GRAFICO 1

PRODUCCIÓN Y PRECIOS DE VENTA DE PAPA EN LA FERIA CANTÓN GUAMOTE AÑO 2013

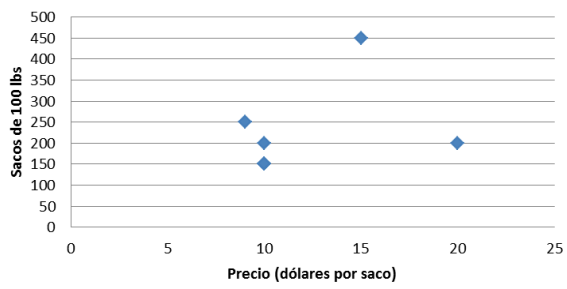

Fuente: Encuesta Feria de Guamote 2013

Elaborado por: Mayra Beltrán Morales, Alfredo Altamirano Ulloa

Por la acción de los intermediarios, las distintas variedades de papa llegan a ofertarse en el Mercado Mayorista de Riobamba donde se aprecian intensas variaciones del precio de venta.

Para el caso de la Gabriela que a inicios del mes de junio del 2011 tuvo un precio mínimo de 10 dólares por quintal de 100 libras, muestra una tendencia creciente hasta un máximo de 28 dólares entre el 9 al 12 de septiembre; además, durante 82 días comprendidos entre el 24 de agosto al 14 de noviembre del 2011, el precio se mantuvo con un promedio de 24 dólares; luego de este período, la tendencia es decreciente hasta mediados de diciembre para estabilizarse hasta marzo del 2012 y vuelve a subir, lo cual demuestra que el comportamiento del precio en Mercado Mayorista de Riobamba de la variedad Gabriela es cíclico, como se ve en el gráfico 2. Estas oscilaciones en el precio de venta significan afectaciones en el nivel de rentabilidad del intermediario que se trasladan al agricultor, pues este busca maximizar su rentabilidad a costa de la vulnerabilidad del productor que no tiene otra alternativa de venta.

Para el caso de la variedad Cecilia, el comportamiento tendencial cíclico es similar con diferencias en el precio de inicio del ciclo en junio del 2011 de 12 dólares, valor máximo de 35 y mínimo de 11 dólares, el valor de 35 se registró de forma puntual en dos ocasiones como se ve en el gráfico 3.

\section{GRÁFICO 2}

COMPORTAMIENTO DE LOS PRECIOS DE LA PAPA GABRIELA EN EL MMR

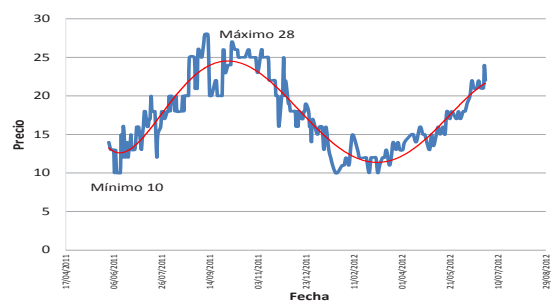

Fuente: SINAGAP-MAGAP 2011

Elaborado por: Mayra Beltrán Morales Alfredo Altamirano Ulloa 
LA ESTRUCTURA DE LA COMERCIALIZACIÓN, FINANCIAMIENTO

$Y$ TRANSPORTE DE LOS PRINCIPALES PRODUCTOS AGRÍCOLAS Y

SU RENTABILIDAD PARA LOS AGRICULTORES DEL CANTÓN GUAMOTE

GRÁFICO 3

COMPORTAMIENTO DE LOS PRECIOS DE LA PAPA CECILIA EN EL MMR

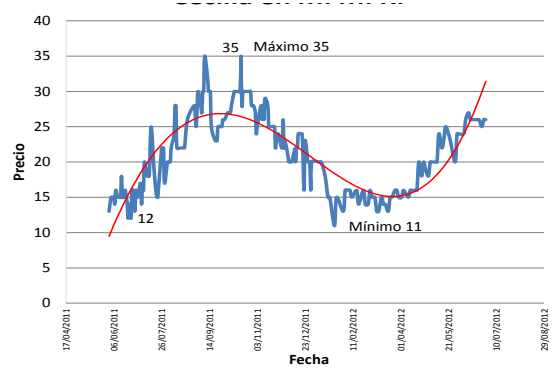

Fuente: SINAGAP-MAGAP 2011

Elaborado por: Mayra Beltrán Morales, Alfredo Altamirano Ulloa

\section{GRÁFICO 4}

COMPORTAMIENTO DE LOS PRECIOS DE LA FRIPAPA EN EL MMR

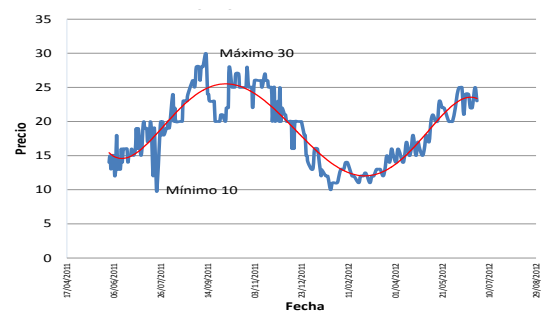

Fuente: SINAGAP-MAGAP 2011

Elaborado por: Mayra Beltrán Morales, Alfredo Altamirano Ulloa

\section{GRÁFICO 5}

COMPORTAMIENTO DE LOS PRECIOS DE LA

SUPERCHOLA EN EL MMR

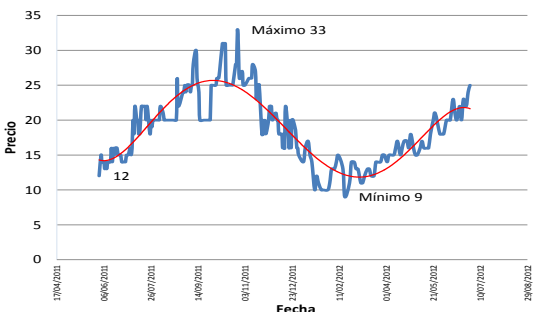

Fuente: SINAGAP-MAGAP 2011

Elaborado por: Mayra Beltrán Morales, Alfredo Altamirano Ulloa

En los gráficos 4 y 5, las variedades Fripapa y Superchola, muestran también el mismo comportamiento cíclico, con variaciones en los precios mínimo, máximo; lo que resalta para el análisis del comportamiento de los precios en el Mercado Mayorista de Riobamba es que los precios varían diariamente aunque en su conjunto muestran el comportamiento cíclico que se menciona, donde la rentabilidad del intermediario se verá afectada en función del lugar que ocupe en la curva el precio al momento de la venta, estas variaciones en los precios agregan mayor presión sobre el agricultor.

Otro destino para la comercialización de la producción guamoteña de papa es la ciudad de Guayaquil, específicamente en el Mercado Mayorista donde se registran los precios de venta diarios de las variedades Fripapa y Superchola que se reflejan en los gráficos 
Revista PUCE, ISSN 1390-7719. Núm.103. 3 de mayo de 2016 -

3 De noviembre de 2016. Alfredo Altamirano UlLoa,

Mayra Beltrán MORALES. PP. $185-231$

6 y 7. El comportamiento tendencial de estos precios de Fripapa es similar al que se observa en Riobamba, con coincidencias en el período de fechas donde se dan los precios mínimo y máximo; esto podría entenderse porque este producto constituye una materia prima para restaurantes y locales de comida rápida, donde en su menú aparece la oferta de papas fritas, cocinadas u otras.

\section{GRÁFICO 6}

COMPORTAMIENTO DE LOS PRECIOS DE

LA FRIPAPA EN EL MMR

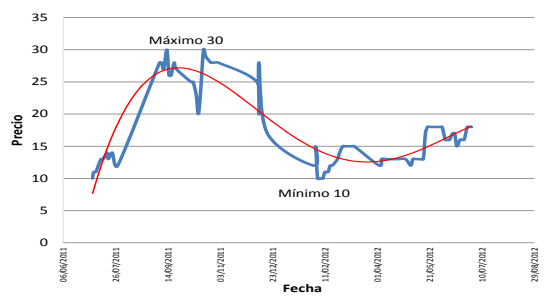

Fuente: SINAGAP-MAGAP 2011, Alfredo Altamirano Ulloa

La variedad de papa Superchola que se comercializa en el mercado mayorista de Guayaquil presenta un comportamiento un tanto diferente como se aprecia en el gráfico 7, a pesar de lo cual existen coincidencias en las temporadas de subida y bajada de precios, donde se registra un precio superior de siete dólares con relación a la Fripapa.

\section{GRÁFICO 7}

COMPORTAMIENTO DE LOS PRECIOS

DE LA SUPERCHOLA EN EL MMG

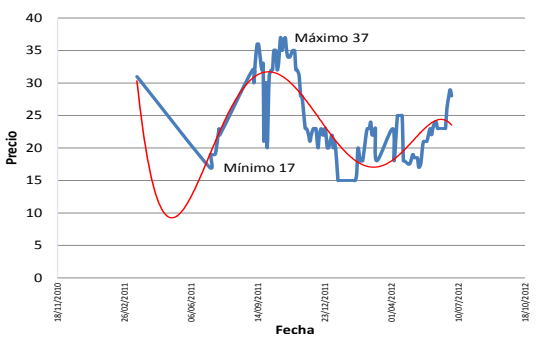

Fuente: SINAGAP-MAGAP 2011

Elaborado por: Mayra Beltrán Morales, Alfredo Altamirano Ulloa

El comportamiento de los precios de todas las variedades guarda relación con los períodos de siembra y cosecha que se pueden apreciar en la tabla 11, donde la primera siembra de las tres parroquias se da en los meses de mayo y junio, período en el cual los precios se encuentran en ascenso. La segunda siembra en las parroquias Guamote y Cebadas se realiza en noviembre y diciembre, mientras que en Palmira se prolonga hasta enero, período en el cual los precios descienden. El primer período de cosecha es de diciembre a febrero en la parroquia Cebadas mientras que en Guamote es de enero a febrero y en Palmira se extiende hasta marzo, donde se dan los precios más bajos de la curva. La segunda cosecha es entre julio y agosto en Guamote y Cebadas y hasta septiembre en Palmira, etapa en la cual los precios suben. 
LA ESTRUCTURA DE LA COMERCIALIZACIÓN, FINANCIAMIENTO

Y TRANSPORTE DE LOS PRINCIPALES PRODUCTOS AGRÍCOLAS Y

SU RENTABILIDAD PARA LOS AGRICULTORES DEL CANTÓN GUAMOTE

\section{Oferta de maíz suave choclo}

Se identifica que la producción de maíz suave choclo (variedad blanco) se concentra en la parroquia Cebadas, con un $96.85 \%$ del total cantonal, así mismo en la tabla 4 se puede observar que el $97.2 \%$ se destina al autoconsumo, lo cual deja un $2.8 \%$ para la comercialización. Por lo expuesto el maíz contribuye a garantizar la seguridad alimentaria del cantón.

\section{TABLA 8}

PRODUCCIÓN DE MAÍZ SUAVE

CHOCLO CANTÓN GUAMOTE 2011

\begin{tabular}{|c|c|c|c|c|}
\hline \multicolumn{5}{|c|}{ PRODUCCIÓN ENTM } \\
\hline $\begin{array}{c}\text { PRODUCTOS } \\
\text { POR } \\
\text { VARIEDAD }\end{array}$ & GUAMOTE & CEBADAS & PALMIR A & $\begin{array}{c}\text { LUGAR DE } \\
\text { VENTA }\end{array}$ \\
\hline Blanco & 33 & 1.015 & & \multirow{2}{*}{ 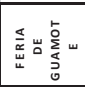 } \\
\hline $\begin{array}{c}\text { TOTALDE } \\
\text { MAÍZ SUAVE }\end{array}$ & 33 & 1.015 & & \\
\hline
\end{tabular}

Fuente: SINAGAP-MAGAP 2011

Elaborado por: Mayra Beltrán Morales

Alfredo Altamirano Ulloa

\section{GRÁFICO 8}

PRODUCCIÓNY PRECIOS DEVENTA DE MAÍZ SUAVE CHOCLO EN LA FERIA CANTÓN GUAMOTE 2013

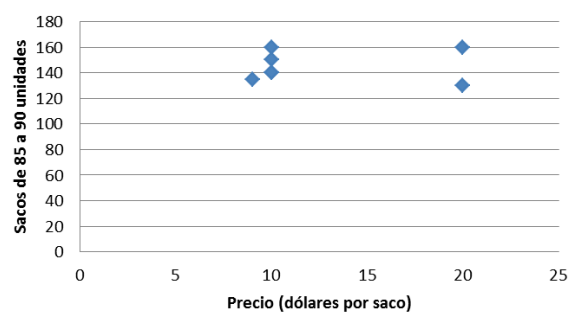

Fuente: Encuesta Feria de Guamote 2013

Elaborado por: Mayra Beltrán Morales Alfredo Altamirano Ulloa

\section{GRÁFICO 9}

COMPORTAMIENTO DE LOS PRECIOS DEL MAÍZ SUAVE EN EL MMR

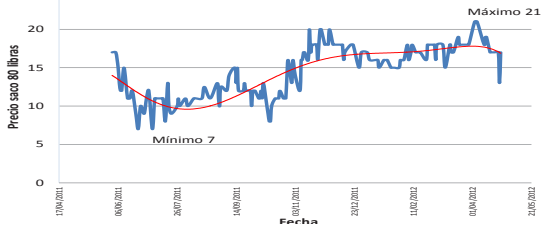

Fuente: SINAGAP-MAGAP 2011

Elaborado por: Mayra Beltrán Morales Alfredo Altamirano Ulloa

En el gráfico 9, se observa que los precios de venta de este producto en el mercado mayorista de Riobamba registran un valor mínimo de 7 dólares el saco de 80 libras y un máximo de 21. Los más frecuentes se registran entre el 6 de septiembre y el 29 de diciembre del 2011 en Riobamba a 11 dólares el saco de 80 libras. El comportamiento de los precios cambia diariamente con subidas y bajadas, adicionalmente existen dos períodos de cosecha: el primero en tierno que corresponde a los meses de mayo y junio donde los precios bajan y el segundo en seco que comprende a los meses de julio y agosto donde se estabilizan en la parte descendente de la curva e inicia una tendencia al alza que coincide con el período de siembra que va de septiembre a noviembre (ver tabla 11). 
ReVista PUCE. ISSN 1390-7719. Núm.103. 3 de mayo de 2016 -

3 De noviembre de 2016. Alfredo Altamirano UlLoa, Mayra Beltrán MORALEs. PP. $185-231$

GRÁFICO 10

COMPORTAMIENTO DE LOS PRECIOS DEL MAÍZ SUAVE EN EL MMG

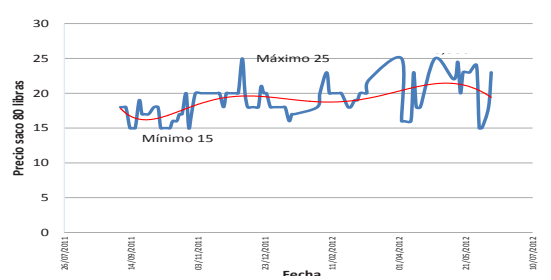

Fuente: SINAGAP-MAGAP 2011

Elaborado por: Mayra Beltrán Morales

Alfredo Altamirano Ulloa

Asimismo, en el mercado mayorista de Guayaquil (gráfico 10), los precios mínimos y máximos varían desde 15 hasta 25 dólares el saco de 80 libras, lo cual refleja un encarecimiento del producto para llegar a este mercado. La línea de tendencia es fluctuante donde el precio más frecuente es de 20 dólares desde el 1 junio al 30 de diciembre del 2011.

Aparentemente existe relación directa entre la variación de los precios por la distancia entre ciudades y los costos de transporte relacionados; pero en este caso no es así, puesto que, al comparar algunos datos del mismo día en los dos mercados mayoristas, se observan valores disimiles que no responden a ningún patrón de comportamiento, lo cual podría deberse a que el producto llega desde distintos lugares de producción.

\section{Oferta de haba tierna en vaina}

En el cantón Guamote existen tres variedades de haba tierna en vaina que se cultivan y son: Huagra sembrada en las tres parroquias y en cantidad es la mayoritaria, la Común es la que menos se cultiva y la Semiverde que se produce solo en Cebadas como se puede apreciar en la tabla 9, de toda esta producción se destina el 79,8\% del producto a la venta en la feria (ver tabla 4).

\section{TABLA 9}

PRODUCCIÓN DE HABA TIERNA EN VAINA CANTÓN GUAMOTE 2011

\begin{tabular}{|c|c|c|c|c|}
\hline \multirow{2}{*}{$\begin{array}{l}\text { PRODUCTOS POR } \\
\text { VARIEDAD }\end{array}$} & \multicolumn{3}{|c|}{ PRODUCCION EN TM } & \multirow{2}{*}{$\begin{array}{l}\text { LUGAR DE } \\
\text { VENTA }\end{array}$} \\
\hline & GUAMOTE & CEBADAS & PALMIRA & \\
\hline Común & 32 & & & \multirow{4}{*}{ 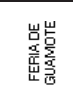 } \\
\hline Huagra & 283 & 325 & 433 & \\
\hline Semi Verde & 32 & & 111 & \\
\hline TOTAL DE HABA TIERNA & 347 & 325 & 544 & \\
\hline
\end{tabular}

Fuente: SINAGAP-MAGAP

Elaborado por: Mayra Beltrán Morales, Alfredo Altamirano Ulloa

\section{GRÁFICO 11}

PRODUCCIÓN Y PRECIOS DE VENTA DE HABA TIERNA EN VAINA EN LA FERIA CANTÓN GUAMOTE 2013

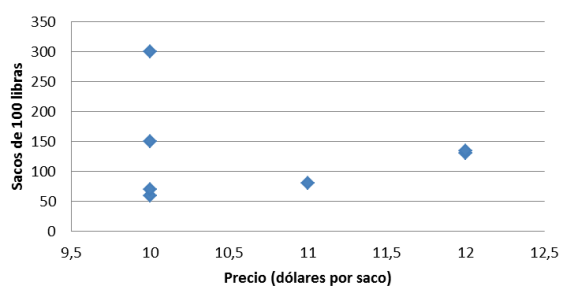

Fuente: Encuesta Feria de Guamote 2013

Elaborado por: Mayra Beltrán Morales, Alfredo Altamirano Ulloa 
GRÁFICO 12

COMPORTAMIENTO DE LOS PRECIOS DE HABA TIERNA EN EL MMR

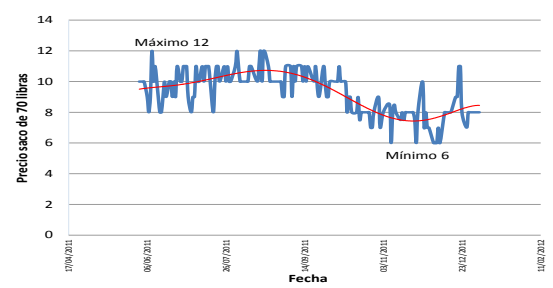

Fuente: SINAGAP-MAGAP

Elaborado por: Mayra Beltrán Morales, Alfredo Altamirano Ulloa

En el gráfico 12 el precio más frecuente se aproxima a 10 dólares el saco de 70 libras con una tendencia cíclica que se inicia con un ascenso de los precios en el mes de junio hasta llegar a un valor máximo de 12 dólares para luego decrecer a mediados de noviembre hasta 6 dólares. Los precios se mantienen cercanos a la línea de tendencia, esto podría deberse a que hay dos períodos de siembra y cosecha al año lo cual genera abastecimiento del producto de forma permanente en Riobamba.
GRÁFICO 13

COMPORTAMIENTO DE LOS PRECIOS DE HABA TIERNA EN EL MMG

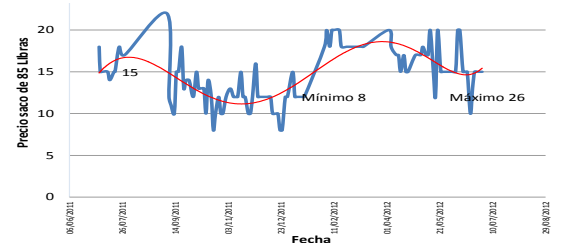

Fuente: SINAGAP-MAGAP

Elaborado por: Mayra Beltrán Morales, Alfredo Altamirano Ulloa

En el mercado mayorista de Guayaquil los precios son más altos con un valor mínimo de 8 dólares entre noviembre y diciembre y un máximo de 26 dólares en septiembre. Muestran mayor inestabilidad en la cotización diaria de venta (ver gráfico 13) lo que se relaciona con costos de transporte e intermediación; además el haba no es característica de los platos típicos costeños y de su cultura culinaria diaria, lo que podría influenciar en esta variación de precios, razón por la cual los comerciantes acostumbran bajarlos para no quedarse con el producto, pues es perecible ya que para su conser- 
ReVista PUCE. ISSN 1390-7719. Núm.103. 3 de mayo de 2016 -

3 De noviembre de 2016. Alfredo Altamirano UlLoA, Mayra Beltrán Morales. PP, 185-231

vación se requiere refrigeración, proceso que en la práctica no se aplica.

\section{Oferta de cebada}

En el caso de la cebada, el análisis que se presenta es limitado, esto se debe a que el MAGAP no registra los datos correspondientes a precios de venta en los mercados mayoristas de Riobamba y Guayaquil, como es en todos los casos anteriores. En este contexto se muestra en la tabla 10 la información de producción por parroquias, donde se observa que la variedad Franciscana se produce en todo el territorio, mientras que las otras variedades no se utilizan en la parroquia Cebadas. Resalta Palmira que produce 716 toneladas de un total de 1.097 equivalente al 65\%, del cual la variedad malta es la más importante.

TABLA 10

PRODUCCIÓN DE CEBADA CANTÓN

GUAMOTE AÑO 2011

\begin{tabular}{|c|c|c|c|c|}
\hline \multicolumn{5}{|c|}{ PRODUCCIÓN EN TM } \\
\hline $\begin{array}{c}\text { PRODUCTOS } \\
\text { POR } \\
\text { VARIEDAD }\end{array}$ & GUAMOTE & CEBADAS & P A L M IR A & $\begin{array}{c}\text { LUGAR DE } \\
\text { VENTA }\end{array}$ \\
\hline Común & 32 & & & \multirow{4}{*}{ 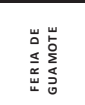 } \\
\hline Huagra & 283 & 325 & 433 & \\
\hline Semiverde & 32 & & 111 & \\
\hline $\begin{array}{c}\text { TOTALDE } \\
\text { HABA TIERNA }\end{array}$ & 347 & 325 & 544 & \\
\hline
\end{tabular}

Fuente: SINAGAP-MAGAP

Elaborado por: Mayra Beltrán Morales, Alfredo Altamirano Ulloa

\section{GRÁFICO 14}

PRODUCCIÓN Y PRECIOS DE VENTA DE CEBADA EN LA FERIA CANTÓN GUAMOTE AÑO 2013

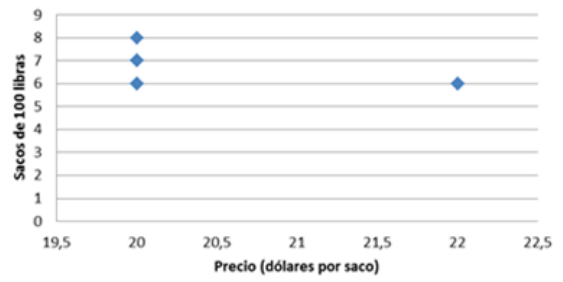

Fuente: Encuesta Feria de Guamote 2013

Elaborado por: Mayra Beltrán Morales, Alfredo Altamirano Ulloa

\section{Temporalidad de la siembra}

La inestabilidad de los precios en todos los productos podría relacionarse con la temporalidad de los procesos desde la siembra hasta la cosecha; en el cantón, estas fechas no varían significativamente y la temporada de cosecha se concentra entre los meses de julio y diciembre; adicionalmente, son pocos los casos en los que se realizan dos siembras al año como se puede apreciar en la tabla 11. 
LA ESTRUCTURA DE LA COMERCIALIZACIÓN, FINANCIAMIENTO

Y TRANSPORTE DE LOS PRINCIPALES PRODUCTOS AGRÍCOLAS Y

SU RENTABILIDAD PARA LOS AGRICULTORES DEL CANTÓN GUAMOTE

TABLA 11

PERÍODOS DE SIEMBRA-COSECHA

\begin{tabular}{|c|c|c|c|c|c|c|}
\hline \multirow{2}{*}{ ACTIVIDAD } & \multicolumn{2}{|c|}{ GUAMOTE } & \multicolumn{2}{|c|}{ CEBADAS } & \multicolumn{2}{|c|}{ PALMIRA } \\
\hline & PRIMERA & SEGUNDA & PRIMERA & SEGUNDA & PRIMERA & SEGUNDA \\
\hline Preparación de terreno & Enero a abril & Septiembre a octubre & Febrero a abril & Septiembre a octubre & Enero a mayo & Septiembre a noviembre \\
\hline Siembra & Mayo a junio & Noviembre a diciembre & Mayo a junio & Noviembre a diciembre & Mayo a junio & Noviembre a enero \\
\hline \begin{tabular}{|l|} 
Fumigación \\
\end{tabular} & Julio a agosto & Febrero a marzo & Julio a agosto & Febrero a marzo & Julio a agosto & Febrero a marzo \\
\hline Deshierba & Julio a agosto & Febrero a marzo & Julio a agosto & Febrero a marzo & Julio a agosto & Febrero a marzo \\
\hline Fumigación & Octubre a noviembre & Mayo a junio & Octubre a noviembre & Mayo a junio & Octubre a diciembre & Mayo a julio \\
\hline \begin{tabular}{|l|} 
Aporque \\
\end{tabular} & Octubre a noviembre & Mayo a junio & Octubre a noviembre & Mayo a junio & Octubre a diciembre & Mayo a julio \\
\hline \begin{tabular}{|l|} 
Cosecha \\
\end{tabular} & Enero a febrero & Julio a agosto & Diciembre a febrero & Julio a agosto & Enero a marzo & Agosto a septiembre \\
\hline Preparación de terreno & Septiembre & & Septiembre & Septiembre & & \\
\hline \begin{tabular}{|l|l|} 
Siembra \\
\end{tabular} & & & Noviembre a diciembre & Septiembre a noviembre & & \\
\hline Cosecha & & & Agosto a septiembre & Agosto a septiembre & & \\
\hline Preparación de terreno & Agosto a septiembre & & Abril a mayo & Agosto a septiembre & & \\
\hline Siembra & Septiembre a octubre & & Junio a julio & Septiembre a octubre & & \\
\hline Deshierba & Diciembre a enero & & Agosto a septiembre & Diciembre a enero & & \\
\hline Fumigación & Diciembre a enero & & Agosto a septiembre & Diciembre a enero & & \\
\hline Cosecha en tierno & Marzo a abril & & Noviembre a diciembre & Marzo a abril & & \\
\hline \begin{tabular}{|l|} 
Cosecha en seco \\
\end{tabular} & Agosto a septiembre & & Enero a febrero & Agosto a septiembre & & \\
\hline Preparación de terreno & & & Junio a julio & & & \\
\hline Siembra & & & Septiembre a noviembre & & & \\
\hline Deshierba & & & Diciembre a enero & & & \\
\hline Aporque & & & Marzo a abril & & & \\
\hline Cosecha en tierno & & & Mayo a junio & & & \\
\hline Cosecha en seco & & & Julio a agosto & & & \\
\hline
\end{tabular}

Fuente: Equipo técnico PARLAMENTO INDÍGENA Y POPULAR DE GUAMOTE. 2001

Elaborado por: Mayra Beltrán Morales, Alfredo Altamirano Ulloa

GRÁFICO 15

PRECIOS EN TEMPORADA DE COSECHA DE LAS VARIEDADES DE PAPA EN MMR - 2011

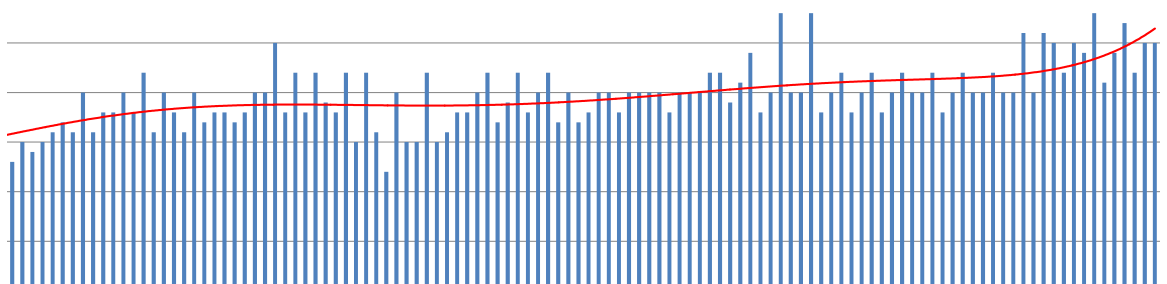

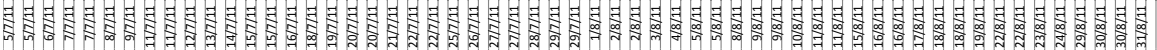

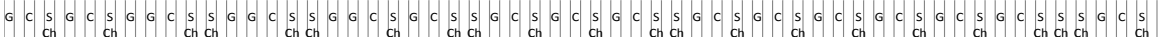
NOTA: La cantidad de información procesada corresponde a la disponible en el MAGAP

$\mathrm{G}=$ variedad Gabriela

$\mathrm{C}=$ variedad Cecilia

$\mathrm{S} C h=$ variedad Super Chola

Fuente: SINAGAP-MAGAP 2011

Elaborado por: Mayra Beltrán Morales, Alfredo Altamirano Ulloa

En el gráfico 15 con base en las fechas de cosecha se extracta los precios de venta de las variedades de papa en el Mercado Mayorista de Riobamba en el cual se evi- 
Revista PUCE, ISSN 1390-7719. Núm.103. 3 de MAYO de 2016 -

3 De noviembre de 2016. Alfredo Altamirano UlLoA,

Mayra Beltrán MORALES. PP. $185-231$

dencia su inestabilidad que, para el caso de Riobamba, se encuentra mayoritariamente entre 15 y 20 dólares el quintal de 100 libras en el período de julio a agosto del año 2011.

\section{GRÁFICO 16}

PRECIOS EN TEMPORADA DE COSECHA DE PAPA

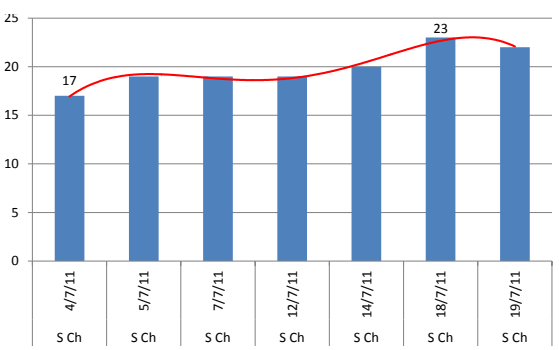

NOTA: La cantidad de información procesada corresponde a la disponible en el MAGAP

$\mathrm{S} C \mathrm{C}=$ variedad Superchola

Fuente: SINAGAP-MAGAP

Elaborado por: Mayra Beltrán Morales, Alfredo Altamirano Ulloa
Igualmente, en el gráfico 16 se registran los datos de Guayaquil donde el precio es más cercano a los 20 dólares. Esta diferencia de cinco dólares se justifica por los costos de transporte e intermediación existentes.

\section{GRÁFICO 17}

PRECIOS EN TEMPORADA DE COSECHA DE MAÍZ SUAVE MMR

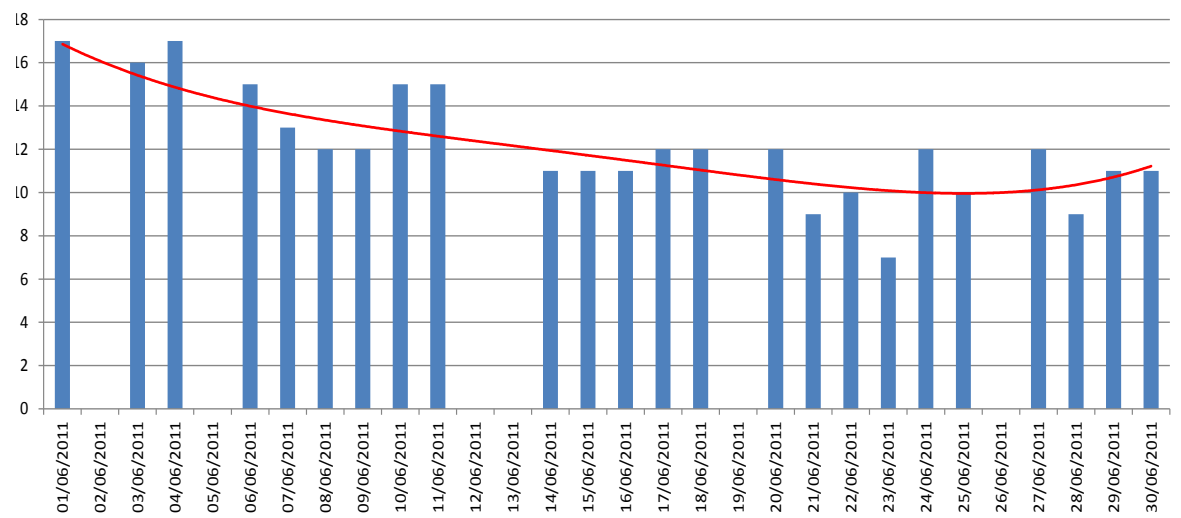

NOTA: La cantidad de información procesada corresponde a la disponible en el MAGAP

Fuente: SINAGAP-MAGAP

Elaborado por: Mayra Beltrán Morales, Alfredo Altamirano Ulloa 
Para el caso del Maíz Suave Choclo, no existe información sobre los precios de venta en Guayaquil y en el Mercado Mayorista de Riobamba (ver gráfico 17); se evidencia un decrecimiento en la tendencia del precio de venta y esto se debe a que en los meses de mayo a junio se cosecha, por lo tanto, hay mayor oferta del producto que se cotiza en un rango de 10 a 12 dólares el saco.

\section{GRÁFICO 18}

\section{PRECIOS EN TEMPORADA DE COSECHA DE HABA TIERNA EN MMR}

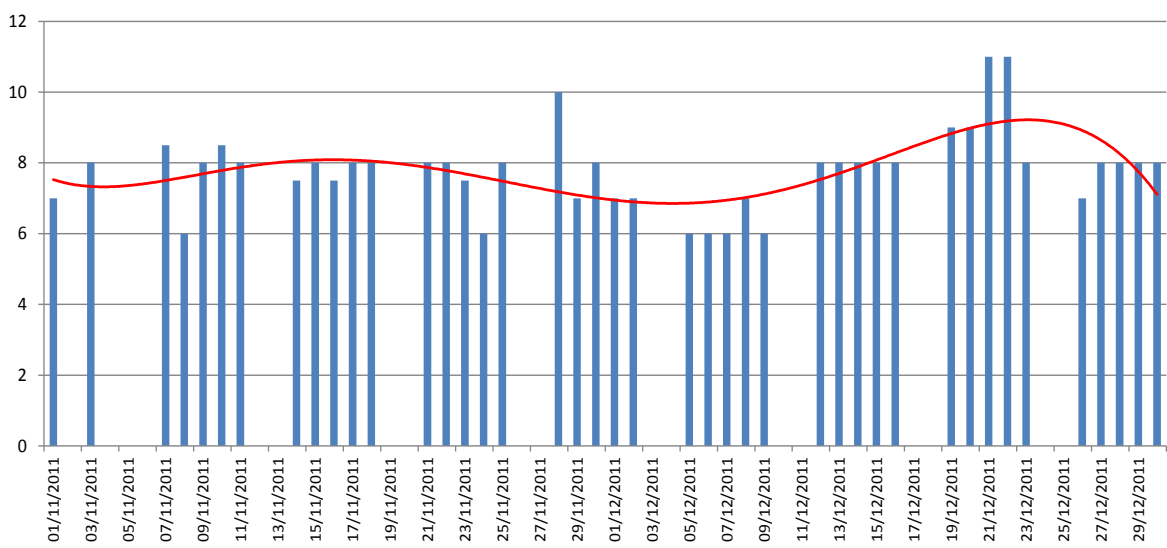

NOTA: La cantidad de información procesada corresponde a la disponible en el MAGAP Fuente: SINAGAP-MAGAP

Elaborado por: Mayra Beltrán Morales, Alfredo Altamirano Ulloa

En el haba tierna en vaina el comportamiento de los precios en Riobamba fluctúan entre 6 y 8 dólares (ver gráfico 18) mientras que en Guayaquil se ubican entre 14 y 16 (ver gráfico 19), esta diferencia en los precios se debería al impacto de la intermediación y el transporte. 
Revista PUCE. ISSN 1390-7719. Núm.103. 3 de mayo de 2016-

3 de noviembre de 2016. Alfredo altamirano Ulloa, Mayra beltrán Morales. PP. 185-231

\section{GRÁFICO 19}

PRECIOS EN TEMPORADA DE COSECHA DE HABA TIERNA EN MMG

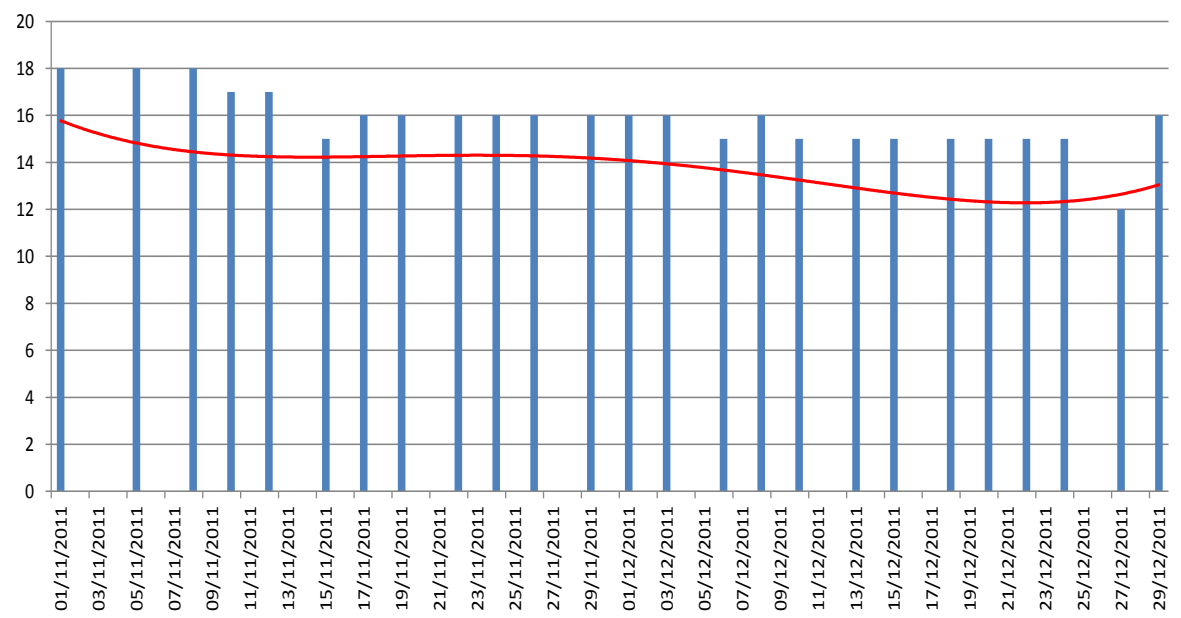

NOTA: La cantidad de información procesada corresponde a la disponible en el MAGAP

Fuente: SINAGAP-MAGAP

Elaborado por: Mayra Beltrán Morales, Alfredo Altamirano Ulloa

\section{EL SISTEMA DE TRANSPORTE DE PRODUCTOS}

En la provincia de Chimborazo existen 157 operadoras de las diferentes modalidades de transporte, con un total de 4.678 unidades; las modalidades intra e interprovincial y carga mixta tienen sus unidades dentro del período de vida útil como se establece por la Resolución No 139-DIR-2010-CNTTTSV expedida por la Comisión Nacional de Transporte Terrestre, Tránsito y Seguridad Vial, en tanto que en las modalidades de carga pesada, taxi y escolar - institucional el 99,77\%, 96,92\% y $81,94 \%$ respectivamente cumplen con lo dispuesto en la resolución antes men- cionada. Con respecto a la modalidad de carga liviana se visibiliza que solo el $56,95 \%$ de sus unidades están dentro del período de vida útil (INEC, 2001).

\section{La informalidad del transporte}

La mayor cantidad de vehículos matriculados en la provincia son camionetas luego automóviles, jeep's, camiones y motocicletas; esta realidad obedece a que se desarrollan primordialmente actividades rurales, que requieren la movilización de los productos generados en las UPA's hasta los centros de acopio o sitios de ex- 
LA ESTRUCTURA DE LA COMERCIALIZACIÓN, FINANCIAMIENTO

Y TRANSPORTE DE LOS PRINCIPALES PRODUCTOS AGRÍCOLAS Y

SU RENTABILIDAD PARA LOS AGRICULTORES DEL CANTÓN GUAMOTE

pendio y venta. El porcentaje de camionetas adquiridas frente al total nacional alcanza únicamente el 3,79\% (ver tabla 12).

\section{TABLA 12}

VEHÍCULOS MOTORIZADOS MATRICULADOS EN CHIMBORAZO

\begin{tabular}{|l|c|c|c|}
\hline \multicolumn{1}{|c|}{ C L A S E } & C H IM B O R A Z O & N A C IO N A L & P O R C E N T A J E \\
\hline CAMIONETA & 8.194 & 216.459 & $3,79 \%$ \\
\hline AUTOMÓVIL & 7.849 & 329.184 & $2,38 \%$ \\
\hline JEEP & 3.420 & 148.063 & $2,31 \%$ \\
\hline CAMIÓN & 2.932 & 58.216 & $5,04 \%$ \\
\hline MOTOCICLETA & 2.311 & 106.979 & $2,16 \%$ \\
\hline OTRA CLASE & 544 & 14.841 & $3,67 \%$ \\
\hline TRAILES & 307 & 4.474 & $6,86 \%$ \\
\hline VOTE & 302 & 7.814 & $3,86 \%$ \\
\hline FURGONETA & 251 & 9.952 & $2,52 \%$ \\
\hline BUS & 164 & 5.469 & $3,00 \%$ \\
\hline TANQUERO & 58 & 2.018 & $2,87 \%$ \\
\hline COLECTNO & 11 & 1.049 & $1,05 \%$ \\
\hline FURGONETA & 5 & 1.133 & $0,44 \%$ \\
\hline \multicolumn{1}{|c|}{ TOTAL } & $\mathbf{2 6 . 3 4 8}$ & $\mathbf{9 0 5 . 6 5 1}$ & $\mathbf{2 , 9 1 \%}$ \\
\hline
\end{tabular}

Fuente: INEC, Estadísticas De Transporte 2001 Elaborado por: Mayra Beltrán Morales, Alfredo Altamirano Ulloa

La capacidad de movilización de la producción y su costo está relacionada con la disponibilidad de vehículos que se destinan al transporte de carga existente en el cantón y la provincia, principalmente porque el mercado es local. Al respecto, se aprecia en la tabla 13 que el porcentaje de automotores con capacidad de carga de $1 / 4$ a 3 toneladas no superan el 3,5\% respecto a los totales nacionales. Además, el 3,37\% de la población económicamente activa provincial se dedica a actividades de transporte, almacenamiento y comunicación, mientras que en el cantón es apenas el
1.27\%; lo que significa que hay escasez de medios de transporte ante lo cual se ven obligados a contratar el servicio en otros cantones lo cual incrementa el costo, a más de abusos y maltratos por parte de los transportistas, lo que redunda en que un alto porcentaje de productores optan por utilizar otros medios alternativos como burros, mulares y llamingos, el costo varía en función del volumen de carga y acompañantes (GOBIERNO AUTÓNOMO DESCENTRALIZADO DE LA PROVINCIA DE CHIMBORAZO, 2011).

\section{TABLA 13}

CAPACIDAD DE CARGA DE VEHÍCULOS MATRICULADOS

\begin{tabular}{|l|c|c|c|}
\hline \multicolumn{1}{|c|}{ DE S C R IP C IÓ N } & C H IM B OR A Z O & N A C ION A L & P O R C E N T A J E \\
\hline VEHÍCULOS & 10.553 & 304.955 & $3,5 \%$ \\
\hline CAPACIDAD Tn. & 26.927 & 831.983 & $3,2 \%$ \\
\hline 1/4 A 3 Tn. & 8.877 & 251.343 & $3,5 \%$ \\
\hline 3 1/4 a 6 Tn. & 888 & 29.051 & $3,0 \%$ \\
\hline 6 1/2 a 10 Tn. & 336 & 10.552 & $3,2 \%$ \\
\hline 10 1/2 a 15 Tn. & 284 & 6.575 & $4,3 \%$ \\
\hline $151 / 2$ a más Tn. & 168 & 7.434 & $2,3 \%$ \\
\hline
\end{tabular}

Fuente: INEC, Estadísticas de Transporte 2001

Elaborado por: Mayra Beltrán Morales, Alfredo Altamirano Ulloa

TABLA 14

VEHÍCULOS MATRICULADOS POR USO

\begin{tabular}{|l|c|c|c|}
\hline $\begin{array}{c}\text { US O DE } \\
\text { VE HIC ULO }\end{array}$ & C H IM B OR A Z O & N A C ION A L & P OR C ENTA J E \\
\hline PARTICULAR & 24.997 & 867.387 & $2,9 \%$ \\
\hline ALQUILER & 1.258 & 29.370 & $4,3 \%$ \\
\hline ESTADO & 287 & 7.329 & $3,9 \%$ \\
\hline MUNICIPAL & 101 & 1.565 & $6,5 \%$ \\
\hline \multicolumn{1}{|c|}{ TOTAL } & $\mathbf{2 6 . 6 4 3}$ & $\mathbf{9 0 5 . 6 5 1}$ & \\
\hline
\end{tabular}

Fuente: INEC, Estadísticas de Transporte 2001

Elaborado por: Mayra Beltrán Morales, Alfredo Altamirano Ulloa 
Revista PUCE, ISSN 1390-7719. Núm.103. 3 de mayo de 2016 -

3 De noviembre de 2016. Alfredo Altamirano UlLoa, Mayra Beltrán MORALES. PP. $185-231$

TABLA 15

COMPANÍAS DE TRANSPORTE REGISTRADAS EN LA SUPERINTEN-

DENCIA DE COMPAÑÍAS EN LA PROVINCIA DE CHIMBORAZO

\begin{tabular}{|c|c|c|}
\hline C OMPAÑÍAS REGISTRADASEN LA SUPERINTENDENCIA & C A NTón & CÓdigo CIUU \\
\hline Compañía de camionetas de carga liviana San Carlitos Copasancar S.A. & Guamote & $\mathrm{H} 4923,01$ \\
\hline $\begin{array}{l}\text { Compañía de camionetas de carga liviana mercado mayorista zona centro } \\
\text { Merzocentro S.A. }\end{array}$ & Riobamba & $\mathrm{H} 4923,01$ \\
\hline Compañía de carga y combustible Transpais Cia.Ltda. & Riobamba & $\mathrm{H} 4923,01$ \\
\hline Compañía de transporte de carga pesada Arizona Express S.A. & Riobamba & $\mathrm{H} 4923,01$ \\
\hline Compañía de transporte pesado Benzor S.A. & Riobamba & $\mathrm{H} 4923,01$ \\
\hline & Riobamba & $\mathrm{H} 4923,01$ \\
\hline Compañía de transporte pesado interprovincial Jaime Roldós Aguilera S.A. & Riobamba & $\mathrm{H} 4923,01$ \\
\hline Compañía de transporte pesado Riobamba ciudad bonita RioCIB S.A. & Riobamba & $\mathrm{H} 4923,01$ \\
\hline Compañía de transporte pesado Riobamba unión y progreso Riounpro S.A. & Riobamba & $\mathrm{H} 4923,01$ \\
\hline Compañía de transporte pesado rutas del florecer Transflorecer S.A. & Riobamba & $\mathrm{H} 4923,01$ \\
\hline Compañía de transporte pesado Transferrovial S.A. & Riobamba & $\mathrm{H} 4923,01$ \\
\hline Compañía de transporte pesado Transsucuy S.A. & Riobamba & $\mathrm{H} 4923,01$ \\
\hline Compañía de transporte pesado Virgen de la Peña S.A. & Riobamba & $\mathrm{H} 4923,01$ \\
\hline Compañía de transporte pesado Transcelere Express S.A. & Riobamba & $\mathrm{H} 4923,01$ \\
\hline Díaz Cabrera Compañía de trasnporte pesado S.A. & Riobamba & $\mathrm{H} 4923,01$ \\
\hline Flotrapce S.A. Flota de transporte pesado cerámicas & Riobamba & $\mathrm{H} 4923,01$ \\
\hline Lediyan S.A. & Riobamba & $\mathrm{H} 4923,01$ \\
\hline Mercurytrans Cia. Ltda. & Riobamba & $\mathrm{H} 4923,01$ \\
\hline Rutas chimboracenses S.A. & Riobamba & $\mathrm{H} 4923,01$ \\
\hline Servicios estratégicos de derivados del petróleo Serpetrol Cia. Ltda. & Riobamba & $\mathrm{H} 4923,01$ \\
\hline Transespaña Cia. Ltda. & Riobamba & $\mathrm{H} 4923,01$ \\
\hline Transgavilanes Cia. Ltda. & Riobamba & $\mathrm{H} 4923,01$ \\
\hline Transporte pesado Ricaurte \& hijos Cia. Ltda. & Riobamba & $\mathrm{H} 4923,01$ \\
\hline Transporte de carga minera Shobol S.A. & Riobamba & $\mathrm{H} 4923,01$ \\
\hline Transportes pesados Granizo Transpegranizo Cia. Ltda. & Riobamba & $\mathrm{H} 4923,01$ \\
\hline Transportes pesados traileros de Chimborazo Traichimb S.A.. & Riobamba & $\mathrm{H} 4923,01$ \\
\hline Transporte Tenemaza Internacional C.A. & Riobamba & $\mathrm{H} 4923,01$ \\
\hline Volquetes de vasija Volquetas S.A. & Riobamba & $\mathrm{H} 4923,01$ \\
\hline Compañía de transporte pesado Alma Chambeña Copalcham S.A. & Chambo & $\mathrm{H} 4923,01$ \\
\hline Compañía de transporte pesado San Juan Evangelista Cotpesaje C.A. & Chambo & $\mathrm{H} 4923,01$ \\
\hline Compañía de transporte de carga pesada Villaunión S.A. & Colta & $\mathrm{H} 4923,01$ \\
\hline Compañía de transporte mixta Lago de Colta S.A. & Colta & $\mathrm{H} 4923,05$ \\
\hline Compañía de transporte de volquetas Fiallos Cia. Ltda. & Guano & $\mathrm{H} 4923,01$ \\
\hline Tanqueros rápidos Guano Tanrag Cia. Ltda. & Guano & $\mathrm{H} 4923,01$ \\
\hline Compañía de camionetas de carga Virgen de Chuquipoguio Cia. Ltda. & Guano & $\mathrm{H} 4923,05$ \\
\hline Compañía de transporte de carga 13 de mayo del cantón Pallatanga S.A. & Pallatanga & $\mathrm{H} 4923,05$ \\
\hline Tranportes y Comercio Palla S.A. Transpalla & Pallatanga & $\mathrm{H} 4923,05$ \\
\hline Volquetas el Cedral Volece C.A. & Penipe & $\mathrm{H} 4923,01$ \\
\hline
\end{tabular}

Fuente: Superintendencia de compañías, www,supercias.gov.ec/consultas/inicio.html, 2012.

Elaborado por: Mayra Beltrán Morales, Alfredo Altamirano Ulloa. 
La propiedad de los vehículos matriculados es mayoritariamente particular seguida por que se los utilizan para fines de alquiler que representan el $4,72 \%$ de los 26.643 registrados en la provincia (ver tabla 14). Al comparar con las empresas de transporte registradas en la Superintendencia de Compañías, se determinó que en el cantón Guamote solo está legalmente constituida la Sociedad Anónima San Carlitos Copa Sancar S.A., mientras que en el cantón Riobamba hay 27 compañías y en el resto de cantones no superan las tres (ver tabla 15). Lo que demuestra la informalidad del servicio de transporte de carga que aparentemente se realiza por particulares y no se encuentra organizado.

\section{EL SISTEMA FINANCIERO PÚBLICO Y PRIVADO COMO APOYO A LAS ACTIVIDADES PRODUCTIVAS}

Por la estructura del sistema financiero nacional y las fuentes de financiamiento utilizadas en el cantón, se cree oportuno desglosar la información crediticia desde los sectores públicos, sistema

\section{GRÁFICO 20}

EVOLUCIÓN DETASAS DE INTERÉS EFECTIVAS MÁXIMAS Y PROMEDIO DEL CRÉDITO PRODUCTIVO

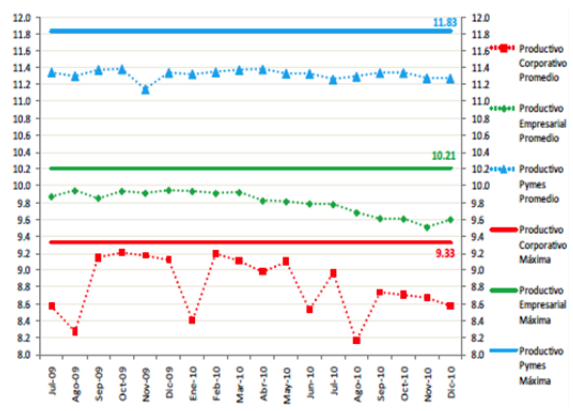

Fuente: Banco Central del Ecuador - enero 2011 Elaborado por: Banco Central del Ecuador - enero 2011 de cooperativas de ahorro y crédito y mutualistas de la provincia de Chimborazo y del cantón Guamote y se analiza los costos del crédito que se visibilizan por medio de las tasas de interés.

\section{GRÁFICO 21}

EVOLUCIÓN DE TASAS DE INTERÉS

EFECTIVAS MÁXIMAS Y PROMEDIO DEL MICRÉDITO

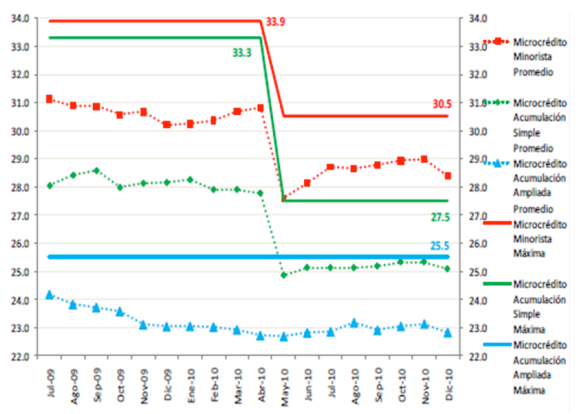

Fuente: Banco Central del Ecuador - enero 2011 Elaborado por: Banco Central del Ecuador - enero 2011 
Revista PUCE, ISSN 1390-7719. Núm.103. 3 de MAYO de 2016 -

3 de noviembre de 2016. Alfredo Altamirano Ulloa, Mayra BELtrán MORALES. PP, 185-231

Para el año 2010, las tasas efectivas promedio para el microcrédito minorista tuvieron un costo que osciló del 28 al 34 por ciento (ver líneas rojas en el gráfico 21), mientras que el crédito productivo para Pymes se ubicó desde el 11 al 11.83 por ciento anual (ver líneas azules en el gráfico 20). Estas tasas de interés elevaron los costos agrícolas, lo que significa que el productor que toma un microcrédito debería pagar 3 veces más el costo financiero que quien califica como pequeño y mediano productor; estas condiciones acentúan la vulnerabilidad de los productores a pequeña escala. De acuerdo con las características socioeconómicas del agricultor guamoteño, se entiende que la mayoría de productores califican para el crédito más caro. Esto quiere decir que los agricultores que se endeudan deberían obtener una rentabilidad superior al 34 por ciento para escasamente cubrir los costos de su deuda, motivo por el cual no existen muchas operaciones de crédito como se aprecia en las siguientes tablas.

\section{Crédito público}

TABLA 16

DISTRIBUCIÓN DEL VOLUMEN DE

CRÉDITO PÚBLICO EN EL CANTÓN GUAMOTE- 2010

\begin{tabular}{|c|c|c|c|}
\hline \multicolumn{2}{|r|}{ ENTIDAD } & $\begin{array}{c}\text { BANCO } \\
\text { NACONAL } \\
\text { DEFOMENTO }\end{array}$ & $\begin{array}{l}\text { CORPORACIÓN } \\
\text { FINANCIERA } \\
\text { NACIONAL }\end{array}$ \\
\hline \multirow{2}{*}{ COMERCIAL } & NÚMERO DE OPERACIONES & 174 & 1 \\
\hline & MONTOOTORGADO & $547.432,38$ & $98.700,00$ \\
\hline \multirow{2}{*}{ consumo } & NÚMER O DE OPERACIONES S & 1 & 0 \\
\hline & MONTO OTORGADO & $8.000,00$ & 0,00 \\
\hline \multirow{2}{*}{ MICROCRÉDTO } & NÚMER O DE OPERACIONES & 664 & 4 \\
\hline & MONTO OTORGADO & $718.004,23$ & $17.999,84$ \\
\hline \multirow{2}{*}{ VINIENDA } & NÚMER O DE OPERACIONES & 0 & 0 \\
\hline & MONTO OTORGADO & 0,00 & 0,00 \\
\hline \multicolumn{2}{|c|}{ TOTAL NÚMERO DE OPERACIONES } & 839,0 & 5 \\
\hline \multicolumn{2}{|c|}{ TOTALMONTOOTORGADO } & $1.273 .436,6$ & 116699,84 \\
\hline
\end{tabular}

Fuente: Superintendencia de Bancos-2010 Elaborado por: Mayra Beltrán Morales Alfredo Altamirano Ulloa

Como se aprecia en la tabla 16, la entidad pública que más operaciones realiza es el Banco Nacional de Fomento y el tipo de crédito más importante tanto en monto como en cantidad es el microcrédito con un promedio de 1.081 dólares por operación crediticia, lo cual responde a la realidad de la población que requiere de montos bajos para financiar entre otras actividades la adquisición de semilla, cubrir los costos de control fitosanitario y cosecha (SUPER-BANCOS, 2010). 


\section{Crédito privado}

En el sistema financiero privado que se representa con las cooperativas de ahorro y crédito registradas en la provincia de Chimborazo, se mantiene el microcrédito como el tipo de operación más importante en cantidad y monto total, del cual el 54\% corresponde a la Cooperativa de Desarrollo de los Pueblos
Codesarrollo, 26\% a Muchucruna y 18\% a la Cooperativa Riobamba (ver tabla 17). Para el caso de las mutualistas no se registraron operaciones de microcrédito en el año 2010; sin embargo, existieron 397 para consumo por un monto total de 1.568.899, con un promedio de 3.951,8 dólares por operación (ver tabla 18).

\section{TABLA 17}

DISTRIBUCIÓN DEL VOLUMEN DE CRÉDITO DE COOPERATIVAS EN EL CANTÓN GUAMOTE- 2010

\begin{tabular}{|c|c|c|c|c|c|c|}
\hline \multicolumn{2}{|c|}{ E NTID A D } & $\begin{array}{l}\text { DE LA PEQUEÑA } \\
\text { EMPRESA DE } \\
\text { COTOPAXI }\end{array}$ & $\begin{array}{c}\text { DESARROLLO } \\
\text { DELOS } \\
\text { PUEBLOS } \\
\text { CODESARROLLO }\end{array}$ & ELSAGRAR IO & R IOB A M B A & MUSHUC RUNA \\
\hline \multirow[t]{2}{*}{ COMERCIAL } & $\begin{array}{c}\text { NÜMERO DE } \\
\text { OPERACIONES }\end{array}$ & 0 & 0 & 1 & 1 & 0 \\
\hline & MONTO OTORGADO & 0,00 & 0,00 & $40.000,00$ & $10.000,00$ & 0,00 \\
\hline \multirow[t]{2}{*}{ CONSUMO } & $\begin{array}{c}\text { NÚMERO DE } \\
\text { OPERACIONES }\end{array}$ & 2 & 0 & 4 & 92 & 3 \\
\hline & MONTO OTORGADO & $5.050,00$ & 0,00 & $20.000,00$ & $382.472,00$ & $4.500,00$ \\
\hline \multirow[t]{2}{*}{ MICROCRÉDITO } & $\begin{array}{c}\text { NÜMERO DE } \\
\text { OPERACIONES }\end{array}$ & 2 & 247 & 1 & 71 & 137 \\
\hline & MONTO OTORGADO & $13.100,00$ & $653.892,00$ & $8.000,00$ & $218.041,00$ & $316.539,00$ \\
\hline \multirow[t]{2}{*}{ VIVIENDA } & $\begin{array}{c}\text { NÜMERO DE } \\
\text { OPERACIONES }\end{array}$ & 0 & 0 & & 8 & 0 \\
\hline & MONTO OTORGADO & 0,00 & 0,00 & & $99.517,00$ & 0,00 \\
\hline \multirow[t]{2}{*}{ TOTAL } & $\begin{array}{l}\text { NÚMERO DE } \\
\text { OPERACIONES }\end{array}$ & 4,00 & 247,00 & 6,00 & 172,00 & 140,00 \\
\hline & MONTO OTORGADO & $18.150,00$ & $653.892,00$ & $68.000,00$ & $710.030,00$ & $321.039,00$ \\
\hline
\end{tabular}

Fuente: Superintendencia de Bancos, 2010.

Elaborado por: Mayra Beltrán Morales, Alfredo Altamirano Ulloa 
ReVista PUCE. ISSN 1390-7719. Núm.103. 3 de mayo de 2016 -

3 De noviembre de 2016. Alfredo Altamirano UlLoa, Mayra Beltrán MORALEs. PP. $185-231$

TABLA 18

DISTRIBUCIÓN DEL VOLUMEN DE CRÉDITO DE MUTUALISTAS EN EL CANTÓN GUAMOTE- 2010

\begin{tabular}{|c|c|c|}
\hline \multicolumn{3}{|c|}{ E N I ID A D } \\
\hline \multirow{2}{*}{ COMERCIAL } & NUMMERO DE OPERACIONES & 2 \\
\cline { 2 - 3 } & MONTO OTORGADO & $65.000,00$ \\
\hline \multirow{2}{*}{ CONSUMO } & NÜMERO DE OPERACIONES & 397 \\
\cline { 2 - 3 } & MONTO OTORGADO & $1.568 .899,00$ \\
\hline \multirow{2}{*}{ MICROCRÉDITO } & NUUMERO DE OPERACIONES & 0 \\
\cline { 2 - 3 } & MONTO OTORGADO & 0,00 \\
\hline \multirow{2}{*}{ VIVIENDA } & NUUMERO DE OPGRACIONES & 167 \\
\cline { 2 - 3 } & MONTO OTORGADO & $3.496 .976,00$ \\
\hline \multirow{2}{*}{ TOTAL } & NÚMERO DE OPERACIONES & $\mathbf{5 6 6}$ \\
\hline \multirow{2}{*}{ TOTAL } & MONTO OTORGADO & $\mathbf{5 . 1 3 0 . 8 7 5 , 0 0}$ \\
\hline
\end{tabular}

Fuente: Superintendencia de Bancos 2010.

Elaborado por: Mayra Beltrán Morales, Alfredo Altamirano Ulloa

En los resultados de la encuesta de línea base del cantón en el año 2010, se evidencia que: "El 51\% de las comunidades no cuentan con ningún tipo de sistema financiero que apoye económicamente para las diferentes actividades que emprende cada familia, mientras que el 23,97\% cuentan con cajas solidarias que de alguna forma apoyan económica- mente a las familias de este sector" (GAD GUAMOTE, 2011: 61). Esto podría indicar que prácticamente la mitad del cantón no tiene acceso a recursos económicos para inversión o consumo, por lo que el 5,8\% (GAD's GUAMOTE, 2011) recurre a chulqueros por la agilidad y facilidades de acceso al dinero a costa de altas exigencias en garantías reales e intereses (ver tabla 19).

TABLA 19

SISTEMA FINANCIERO DEL CANTON GUAMOTE2010

\begin{tabular}{|l|c|c|}
\hline \multicolumn{1}{|c|}{ P R O C E D E N C IA } & C A N T ID A D & P OR C E N T A J E \\
\hline Banco comunal & 5 & 4,1 \\
\hline Caja solidaria & 29 & 23,7 \\
\hline Cooperativa & 8 & 6,6 \\
\hline Chulquero & 7 & 5,8 \\
\hline Más de dos & 10 & 8,5 \\
\hline Ninguno & 62 & 51,3 \\
\hline \multicolumn{1}{|c|}{ T O T A L } & 121 & 100,0 \\
\hline
\end{tabular}

Fuente: GAD GUAMOTE- Encuesta de Línea Base Elaborado por: Mayra Beltrán Morales, Alfredo Altamirano Ulloa

\section{LA RENTABILIDAD DEL COMERCIO AGRÍCOLA}

Para esta etapa se analiza la rentabilidad de la papa, maíz tierno choclo y el haba a partir de la información registrada en:

- Fichas técnicas del INIAP²

${ }^{2}$ Costos de producción acordes con la metodología recomendada técnicamente por el Instituto Nacional Autónomo de Investigaciones Agropecuarias INIAP.
- Sistema de registro de cotización diaria de los precios de los productos en los Mercados Mayoristas de Riobamba y Guayaquil publicados por el MAGAP.

- Costos de los productos principales de la encuesta de línea base del Gobierno Autónomo Descentralizado de Guamote y encuesta de precios 
LA ESTRUCTURA DE LA COMERCIALIZACIÓN, FINANCIAMIENTO

Y TRANSPORTE DE LOS PRINCIPALES PRODUCTOS AGRICOLAS Y

SU RENTABILIDAD PARA LOS AGRICULTORES DEL CANTÓN GUAMOTE

de venta del productor en la feria de Guamote

\section{Costos de producción referenciales del INIAP}

Los costos de la producción agrícola cantonal se basan en la información publicada por el INIAP, que a nivel de gobierno es la institución oficial encargada de generar innovaciones tecnológicas para contribuir en el desarrollo del sector agropecuario y que apoya el incremento de la producción, productividad y el mejoramiento cualitativo de los productos agropecuarios (INIAP, 2012), que adicionalmente genera la información a través de investigación en el campo y establece elementos del costo.

\section{TABLA 20}

COSTOS DE PRODUCCIÓN Y RENDIMIENTOS PRINCIPALES DE LOS PRODUCTOS AGRICOLAS DE GUAMOTE, DE ACUERDO A LAS FICHAS TÉCNICAS DEL INIAP - 2007

\begin{tabular}{|c|c|c|}
\hline ACTIVIDAD & PAPA & $\begin{array}{c}\text { MAÍZ S UABE } \\
\text { CHOCLO }\end{array}$ \\
\hline Análisis del suelo & $\$ 19,00$ & \\
\hline Preparación del suelo & $\$ 100,00$ & $\$ 146,00$ \\
\hline Variedades & $\$ 475,00$ & \\
\hline Siembra & $\$ 84,00$ & \multirow{2}{*}{$\$ 354,00$} \\
\hline Fertilización & $\$ 1.322,00$ & \\
\hline Labores culturales & $\$ 98,00$ & $\$ 379,00$ \\
\hline Contro químico de malezas & $\$ 69,00$ & \\
\hline Control fitosanitario & $\$ 543,00$ & \\
\hline Cosecha & $\$ 560,00$ & \multirow{2}{*}{$\$ 167,00$} \\
\hline Poscosecha & $\$ 140,00$ & \\
\hline Otros & $\$ 42,00$ & $\$ 147,00$ \\
\hline COSTOS DIRECTOS & $\$ 3.453,00$ & $\$ 1.193,00$ \\
\hline RENDIMIENTO kg/ha & 30000 & 9093 \\
\hline
\end{tabular}

\begin{tabular}{|l|lr|}
\hline \multicolumn{1}{|c|}{ A C T IVID A D } & \multicolumn{2}{|c|}{ H A B A } \\
\hline \hline Preparación del suelo & $\$$ & 108 \\
\hline Mano de obra & $\$$ & 532 \\
\hline Insumos & $\$$ & 380 \\
\hline Otros & $\$$ & 221 \\
\hline \multicolumn{1}{|c|}{ C OS ToS DIR E C Tos } & $\$$ & 1.241 \\
\hline \multicolumn{1}{|c|}{ RE N D IM IE NTO kg / ha } & & 6.000 \\
\hline
\end{tabular}

Fuente: INIAP E. E. Santa Catalina Elaborado por: Mayra Beltrán Morales, Alfredo Altamirano Ulloa

En la tabla 20 se puede apreciar que para la papa, la fertilización recomendada por el INIAP representa un 38\% (\$1.322) del costo directo por hectárea en las condiciones técnicas óptimas, el segundo valor más alto corresponde a la cosecha con un 16\% (\$560) seguido por el control fitosanitario con 15\% (\$ 543) y la compra de semilla 13\% (\$475) lo que totaliza el 82\%. En estas condiciones se generarían rendimientos de 30.000 $\mathrm{kg} / \mathrm{ha}$, que es el valor referencial que se utiliza para el análisis.

De igual manera, para el maíz tierno choclo los elementos de costo tienen otra composición, se destaca el 31,8\% (\$379) de labores culturales seguidas en importancia por la siembra y control fitosanitario con el 29,7\% (\$354) y un 14\% (\$176) de cosecha y pos cosecha, que da en total un 75,5\% del costo por hectárea. En este caso el análisis presentó limitaciones para establecer el rendimiento en kg/ha pues a pesar que la información también es generada por el INIAP, los componentes del costo en las 
ReVista PUCE. ISSN 1390-7719. Núm.103. 3 de mayo de 2016 -

3 De noviembre de 2016. Alfredo Altamirano UlLoa, Mayra Beltrán MORALEs. PP. $185-231$

fichas técnicas no son iguales. Para este caso la ficha establecía rendimiento en unidades por lo que se vio la necesidad transformar a kilos con base a una muestra. $^{3}$ El 73,4\% del costo total del haba se concentra en dos actividades que son mano de obra con el 42,8\% (\$532) e insumos con un $30,6 \%$ (\$380).

TABLA 21

COSTOS DE PRODUCCIÓN AJUSTADOS POR INFLACIÓN

\begin{tabular}{|c|c|c|c|c|c|}
\hline \multirow{2}{*}{ P R ODUC TOS } & \multicolumn{5}{|c|}{ O OSTOS } \\
\cline { 2 - 6 } & $\mathbf{2 0 0 7}$ & $\mathbf{2 0 0 8}$ & $\mathbf{2 0 0 9}$ & $\mathbf{2 0 1 0}$ & $\mathbf{2 0 1 1}$ \\
\hline \hline $\begin{array}{c}\text { INFLAC IÓN } \\
\text { A N UAL }\end{array}$ & & 0,0800 & 0,0431 & $0,03 \mathbf{3 3}$ & 0,0541 \\
\hline PAPA & $\$ 3.453,00$ & $\$ 3.729,00$ & $\$ 3.890,00$ & $\$ 4.019,00$ & $\$ 4.237,00$ \\
\hline MAZ & $\$ 1.193,00$ & $\$ 1.289,00$ & $\$ 1.344,00$ & $\$ 1.39,00$ & $\$ 1.464,00$ \\
\hline HABA & $\$ 1.241,00$ & $\$ 1.341,00$ & $\$ 1.399,00$ & $\$ 1.445,00$ & $\$ 1.523,00$ \\
\hline
\end{tabular}

Nota: Los costos han sido ajustados de acuerdo con los índices de inflación oficiales

Fuente: INIAP E. E. Santa Catalina

Elaborado por: Mayra Beltrán Morales, Alfredo Altamirano Ulloa

En razón que los últimos costos de producción oficiales encontrados datan del año 2007 se vio la necesidad de ajustarlos de acuerdo con los índices de inflación anual que se publicaron hasta el 2011, pues como es conocido los productos de primera necesidad se afectan de manera directa por este indicador lo cual se refleja en la tabla 21.

\footnotetext{
${ }^{3}$ Tres chochos equivalen a 0,682 kilogramos
}

\section{Costos de producción referenciales Encuesta de Línea Base Guamote}

De acuerdo con la información de costos de producción y rendimientos levantados en el año 2011 por el Gobierno Autónomo Descentralizado de Guamote que se resume en la tabla 22, el capital invertido en el proceso de producción es distante al elaborado por el INIAP de acuerdo con las condiciones técnicas óptimas, lo cual evidencia que los procesos productivos son empíricos y se sustentan en prácticas tradicionales, aspecto que incide en que los niveles de rendimiento sean de pequeña escala.

TABLA 22

COSTOS DE PRODUCCIÓN Y RENDIMIENTOS REFERENCIALES DE LOS PRINCIPALES PRODUCTOS DEL CANTÓN GUAMOTE- 2011

\begin{tabular}{|c|c|c|c|c|}
\hline \multirow[b]{2}{*}{ PARROQUIAS } & \multicolumn{2}{|c|}{ PAPA } & \multicolumn{2}{|c|}{ CEB A D A } \\
\hline & $\operatorname{Costo}(\mathrm{Ha})$ & $\begin{array}{l}\text { RE E D IM IENTO } \\
\text { (S aco } 100 \mathrm{lb})\end{array}$ & $\operatorname{costo}(\mathrm{Ha})$ & $\begin{array}{l}\text { RENDIMIENTO } \\
\text { (S aco } 100 \mathrm{lb})\end{array}$ \\
\hline MATRZ & 471,00 & 175 & 184,00 & 20 \\
\hline PALMIRA & $\$ \quad 570,75$ & 178 & 298,75 & 26 \\
\hline CEBADAS & 553,00 & 293 & 180,00 & 16 \\
\hline TOTAL & $\$ \quad 531,58$ & 215 & 220,92 & 21 \\
\hline
\end{tabular}

\begin{tabular}{|c|c|c|c|c|}
\hline & \multicolumn{2}{|c|}{ HABA } & \multicolumn{2}{|c|}{ MAíz } \\
\hline PARR OQUIAS & $\cos t o s$ (Ha) & 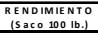 & $\cos t o s(H a)$ & 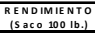 \\
\hline MATRIZ & $\$ 288,00$ & 144 & $\$ 238,00$ & 30 \\
\hline \begin{tabular}{|l|} 
PALMIRA \\
\end{tabular} & $\$ 442,75$ & 103 & $\$ 140,00$ & 15 \\
\hline C巴ADAS & $\$ 365,38$ & 124 & $\$ 65,00$ & 23 \\
\hline TOTAL & $\$ 365,38$ & 124 & $\$ 147,67$ & 23 \\
\hline
\end{tabular}

Fuente: GAD GUAMOTE, Encuesta de Línea Base 2011

Elaborado por: GAD GUAMOTE. 
TABLA 23

COSTOS DE PRODUCCIÓN Y RENDIMIENTOS

REFERENCIALES DE LOS PRINCIPALES PRODUCTOS

DEL CANTÓN GUAMOTE- 2011

\begin{tabular}{|c|c|c|c|c|}
\hline \multirow{2}{*}{ PRODUCTOS } & \multicolumn{2}{|c|}{ INFORMACIÓN INIAP } & \multicolumn{2}{|c|}{ LINEA BASE GUAMOTE } \\
\hline & $\cos \cos (\mathrm{Ha})$ & $\begin{array}{c}\text { RENDIMIENTO } \\
(\mathrm{Kg} / \mathrm{Ha})\end{array}$ & $\cos t \cos (\mathrm{Ha})$ & $\begin{array}{c}\text { RENDIMIENTO } \\
(\mathrm{Kg} / \mathrm{Ha})\end{array}$ \\
\hline PAPA & $4.237,00$ & 30.000 & 531,58 & 9.772 \\
\hline MAZ SUAVE & $1.464,00$ & 6.000 & 220,92 & 935 \\
\hline HABA & $1.523,00$ & 9.093 & 365,38 & 5.613 \\
\hline C BADA & $N / D$ & NDD & 147,67 & 1.045 \\
\hline
\end{tabular}

Nota: Los costos del INIAP se encuentran ajustados por inflación al 2011

Los rendimientos de la Línea Base Guamote se transformaron a Kg.

Fuente: INIAP, GAD GUAMOTE- Encuesta de Línea Base 2011

Elaborado por: Mayra Beltrán Morales, Alfredo Altamirano Ulloa

Al igualar las unidades de medida de costos y rendimientos de los productos, se evidencia que en el caso de la papa guamoteña con una inversión de un poco más del 10\% $(\$ 531,58)$ se obtiene cerca de la tercera parte $(9.093 \mathrm{Kg} / \mathrm{Ha})$ del rendimiento que establece el INIAP; algo similar sucede con el haba, que con una inversión de un poco más el 20\% (\$ $365,38)$ el rendimiento alcanza el 61,70\% ( $5.613 \mathrm{Kg} / \mathrm{Ha})$; en el maíz suave choclo la baja inversión de \$220,92 es compatible con un bajo rendimiento que alcanza al $15.5 \%$ (935 Kg/Ha) de lo que se debe cosechar de acuerdo con la ficha técnica del INIAP. (ver tabla 23). Esta realidad de una productividad baja impacta de manera desfavorable en la rentabilidad de los productores campesinos.

\section{Costos de producción referenciales Trabajo de Campo en la Feria de Guamote}

Para completar el análisis de los datos de costos y rendimientos, se levantó información primaria en la Feria de Guamote, de los productos principales del cantón. En el caso de la papa, los costos y rendimientos promedios son similares a los datos de la encuesta de línea base del GAD Guamote, lo cual a primera vista indica que los datos son certeros y que los rendimientos reales están alrededor de los 10.000 kg por hectárea (ver tablas 23 y 24), lo que representa un tercio del rendimiento óptimo como lo señala el INIAP.

TABLA 24

COSTOS DE PRODUCCIÓN Y RENDIMIENTOS REFERENCIALES FERIA DE GUAMOTE- 2013

\begin{tabular}{|c|c|c|}
\hline \multirow{2}{*}{ PRODUCTOS } & \multicolumn{2}{|c|}{$\begin{array}{l}\text { INFORMACIÓN DE TRABAJO DE CAMPO } \\
\text { FERIA DE GUAMOTE } 2013\end{array}$} \\
\hline & $\cos \operatorname{tos}(\mathrm{Ha})$ & $\begin{array}{l}\text { R E N D IM IE N TO } \\
(\mathrm{Kg} / \mathrm{Ha} \text { a.) }\end{array}$ \\
\hline PAPA & 526 & 10.065 \\
\hline MAIZZ SUAVE & 261 & 2.576 \\
\hline HABA & 450 & 6.591 \\
\hline CEBADA & 136 & 299 \\
\hline
\end{tabular}

Fuente: Encuesta en la Feria de Guamote 2013

Elaborado por: Mayra Beltrán Morales, Alfredo Altamirano Ulloa

La información del maíz muestra diferencias entre la encuesta de línea base del GAD Guamote y de la Feria, el 
Revista PUCE. ISSN 1390-7719. Núm.103. 3 de mayo de 2016 -

3 De noviembre de 2016. Alfredo Altamirano UlLoa, Mayra Beltrán Morales. PP. 185-231

costo de producción por hectárea es similar; sin embargo, los rendimientos que señalan los encuestados son casi el triple; esto podría deberse a que la información de línea base fue levantada por zonas, mientras que los encuestados de esta investigación estaban en la feria y no fue posible identificar la zona de la que provienen. De todas maneras, los rendimientos reales son inferiores a los $6.000 \mathrm{~kg} / \mathrm{ha}$ que establece el INIAP (ver tablas 23 y 24).

En el haba, los costos y rendimientos son similares entre la información del GAD Guamote y la encuesta; de igual manera se encuentran muy por debajo de los establecidos por el INIAP. Llama la atención que con una inversión de apenas 450 dólares obtengan un rendimiento promedio de $6.591 \mathrm{~kg} /$ ha, lo cual representa un poco más de la mitad de los 9.093 kg/ha óptimos. Además, los datos de la cebada a pesar de ser un producto importante en el cantón son marginales, al punto que en los mercados mayoristas de Guayaquil y Riobamba no se registran sus precios de venta.

\section{Rentabilidad}

El análisis de la rentabilidad se calculó al tomar como punto de partida los datos históricos de cotización diaria de precios de venta al público, en los mercados mayoristas de Riobamba y
Guayaquil correspondientes al año 2011, a partir de los cuales se generaron valores estadísticos mínimos, promedio simple, moda y máximo. Estos escenarios permiten identificar una aproximación a la rentabilidad de los intermediarios. Se complementa con el costo por hectárea y precio de venta del productor al consumidor final e intermediario levantada en la feria de Guamote; esto permite establecer los márgenes de utilidad de los agricultores e intermediarios en función de los precios de comercialización en los mercados mayoristas.

Los precios de venta en todas las variedades de papa, en todos los escenarios y en todos los mercados superan el valor de producción del INIAP y de los productores, lo que significa una rentabilidad asegurada para el intermediario que no necesariamente se transfiere al agricultor. En Riobamba, los ingresos mínimos por hectárea que se podrían alcanzar en el escenario óptimo fluctúan entre 5.700 y 7.200 dólares, frente al costo de producción establecido por el INIAP de 4.237; en Guayaquil, se destaca el ingreso mínimo de la variedad superchola que se cotiza en 9.900 (ver tabla 21); asimismo, si se observan los ingresos máximos, se demuestra que el intermediario obtendría una rentabilidad aún mayor, lo cual podría inducirlo a la especulación y explicaría el por qué este es el principal producto del cantón. 
LA ESTRUCTURA DE LA COMERCIALIZACIÓN, FINANCIAMIENTO

$Y$ TRANSPORTE DE LOS PRINCIPALES PRODUCTOS AGRÍCOLAS Y

\|l\|l|II SU RENTABILIDAD PARA LOS AGRICULTORES DEL CANTÓN GUAMOTE

\section{TABLA 25}

ESCENARIOS DE RENTABILIDAD DE LA PAPA POR VARIEDAD

ÓPTIMO (se determina en función del rendimiento establecido por el INIAP)

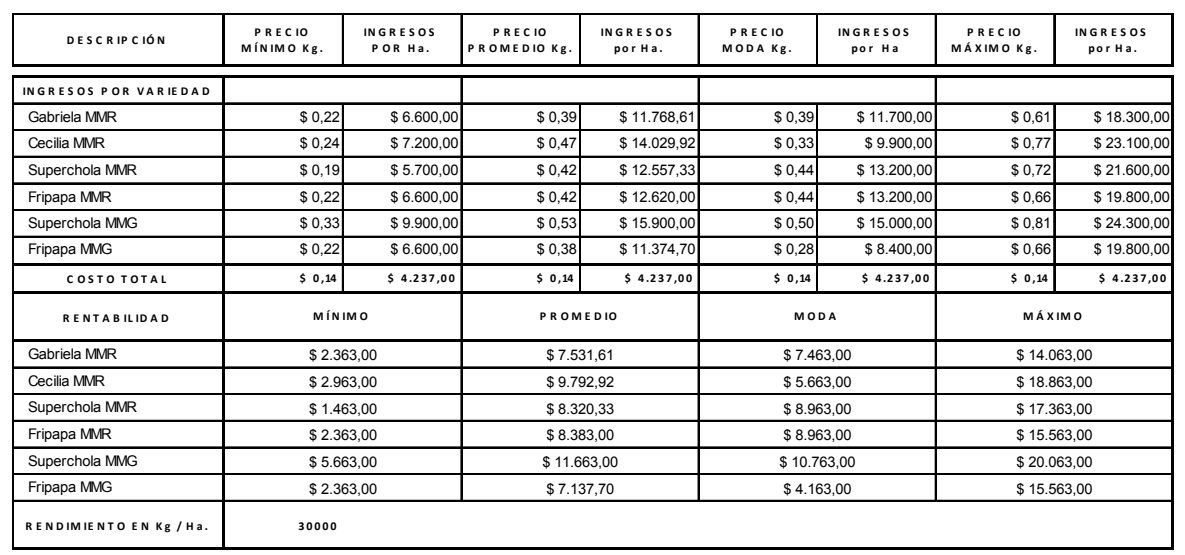

REAL (se determina en función de información primaria de productores)

\begin{tabular}{|c|c|c|c|c|c|c|c|c|}
\hline DESCR IP C IÓN & $\begin{array}{c}\text { PRECIO } \\
\text { MINIMO Kg. }\end{array}$ & $\begin{array}{l}\text { INGRESOS } \\
\text { POR HA. }\end{array}$ & $\begin{array}{c}\text { PRECIO } \\
\text { PROMEDIO Kg. }\end{array}$ & $\begin{array}{l}\text { INGRESOS } \\
\text { porHa. }\end{array}$ & $\begin{array}{l}\text { PRECIO } \\
\text { MODA Kg. }\end{array}$ & $\begin{array}{l}\text { INGRESOS } \\
\text { por Ha }\end{array}$ & $\begin{array}{c}\text { PRECIO } \\
\text { MÁXIMO Kg. }\end{array}$ & $\begin{array}{c}\text { INGRESOS } \\
\text { porHa. }\end{array}$ \\
\hline \multicolumn{9}{|l|}{ INGRESOS POR VARIEDAD } \\
\hline Gabriela MMR & $\$ 0,22$ & $\$ 2.214,30$ & $\$ 0,39$ & $\$ 3.948,37$ & $\$ 0,39$ & $\$ 3.925,35$ & $\$ 0,61$ & $\$ 6.139,65$ \\
\hline Cecilia MMR & $\$ 0,24$ & $\$ 2.415,60$ & $\$ 0,47$ & $\$ 4.707,04$ & $\$ 0,33$ & $\$ 3.321,45$ & $\$ 0,77$ & $\$ 7.750,05$ \\
\hline Superchola MMR & $\$ 0,19$ & $\$ 1.912,35$ & $\$ 0,42$ & $\$ 4.212,99$ & $\$ 0,44$ & $\$ 4.428,60$ & $\$ 0,72$ & $\$ 7.246,80$ \\
\hline Fripapa MMR & $\$ 0,22$ & $\$ 2.214,30$ & $\$ 0,42$ & $\$ 4.234,01$ & $\$ 0,44$ & $\$ 4.428,60$ & $\$ 0,66$ & $\$ 6.642,90$ \\
\hline Superchola MMG & $\$ 0,33$ & $\$ 3.321,45$ & $\$ 0,53$ & $\$ 5.334,45$ & $\$ 0,50$ & $\$ 5.032,50$ & $\$ 0,81$ & $\$ 8.152,65$ \\
\hline Fripapa MMG & $\$ 0,22$ & $\$ 2.214,30$ & $\$ 0,38$ & $\$ 3.816,21$ & $\$ 0,28$ & $\$ 2.818,20$ & $\$ 0,66$ & $\$ 6.642,90$ \\
\hline COSTOTOTAL & $\$ 0,09$ & $\$ 2.657,00$ & $\$ 0,02$ & $\$ 526,00$ & $\$ 0,02$ & $\$ 526,00$ & $\$ 0,02$ & $\$ 526,00$ \\
\hline RENTAB ILIDAD & \multicolumn{2}{|c|}{ MÍNIMO } & \multicolumn{2}{|c|}{ PROMEDIO } & \multicolumn{2}{|c|}{$M O D A$} & \multicolumn{2}{|c|}{ MÁx XIMO } \\
\hline Gabriela MMR & \multicolumn{2}{|c|}{$-\$ 442,70$} & \multicolumn{2}{|c|}{$\$ 1.291,37$} & \multicolumn{2}{|c|}{$\$ 1.268,35$} & \multicolumn{2}{|c|}{$\$ 3.482,65$} \\
\hline Cecilia MMR & \multicolumn{2}{|c|}{$-\$ 241,40$} & \multicolumn{2}{|c|}{$\$ 2.050,04$} & \multicolumn{2}{|c|}{$\$ 664,45$} & \multicolumn{2}{|c|}{$\$ 5.093,05$} \\
\hline Superchola MMR & \multicolumn{2}{|c|}{$-\$ 744,65$} & \multicolumn{2}{|c|}{$\$ 1.555,99$} & \multicolumn{2}{|c|}{$\$ 1.771,60$} & \multicolumn{2}{|c|}{$\$ 4.589,80$} \\
\hline Fripapa MMR & \multicolumn{2}{|c|}{$-\$ 442,70$} & \multicolumn{2}{|c|}{$\$ 1.577,01$} & \multicolumn{2}{|c|}{$\$ 1.771,60$} & \multicolumn{2}{|c|}{$\$ 3.985,90$} \\
\hline Superchola MMG & \multicolumn{2}{|c|}{$\$ 664,45$} & \multicolumn{2}{|c|}{$\$ 2.677,45$} & \multicolumn{2}{|c|}{$\$ 2.375,50$} & \multicolumn{2}{|c|}{$\$ 5.495,65$} \\
\hline Fripapa MMG & \multicolumn{2}{|c|}{$-\$ 442,70$} & \multicolumn{2}{|c|}{$\$ 1.159,21$} & \multicolumn{2}{|c|}{$\$ 161,20$} & \multicolumn{2}{|c|}{$\$ 3.985,90$} \\
\hline RENDIMIENTOEN Kg/Ha. & 10065 & & & & & & & \\
\hline
\end{tabular}

Fuente: MAGAP, Cotización de precios 2011. INIAP Santa Catalina. Encuesta en la Feria de Guamote 2013 Elaborado por: Mayra Beltrán Morales, Alfredo Altamirano Ulloa

Al considerar el rendimiento real de $10.065 \mathrm{Kg} / \mathrm{Ha}$, los ingresos cambian significativamente, al punto que los in- gresos mínimos del escenario óptimo son cercanos a los ingresos máximos del escenario real. En la tabla 25, se registran 
Revista PUCE, ISSN 1390-7719. Núm.103. 3 de mayo de 2016 -

3 De noviembre de 2016. Alfredo Altamirano UlLoA,

Mayra Beltrán Morales. PP. 185-231

los ingresos del intermediario en función de la cotización de precios anual en los mercados mayoristas junto con el costo total, que equivale al valor de venta del agricultor en la feria de Guamote. Se aprecia que, con los precios de venta mínimos, los intermediarios pueden tener pérdidas, mientras que con los precios promedio, los más frecuentes o moda y los máximos obtendrán rentabilidad asegurada. En el gráfico 22, se muestra el escenario real, donde se resaltan los costos e ingresos del agricultor para visualizar su nivel de rentabilidad en relación con el de la intermediación.

\section{GRÁFICO 22}

ESCENARIOS REALES DE RENTABILIDAD DE LA PAPA POR VARIEDAD

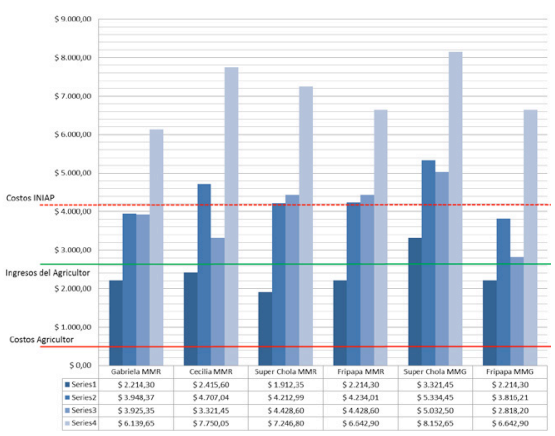

Fuente: MAGAP, Cotización de precios 2011.

INIAP E. E. Santa Catalina

Elaborado por: Mayra Beltrán Morales, Alfredo Altamirano Ulloa

TABLA 26

RENTABILIDAD DE LA HABA TIERNA EN VAINA

ÓPTIMO (se determina en función del rendimiento establecido por el INIAP)

\begin{tabular}{|c|c|c|c|c|c|c|c|c|}
\hline DESCRIPCIÓN & $\begin{array}{c}\text { PRECIO } \\
\text { MINIMO POI KE. }\end{array}$ & $\begin{array}{l}\text { INGRESOS } \\
\text { por Ha. }\end{array}$ & $\begin{array}{c}\text { PRECIO } \\
\text { PROMEDIO por } \\
\text { Kg. }\end{array}$ & $\begin{array}{l}\text { INGRESOS } \\
\text { porHa. }\end{array}$ & $\begin{array}{l}\text { PRECIO MODA } \\
\text { por Kg. }\end{array}$ & $\begin{array}{l}\text { INGRESOS } \\
\text { porHa. }\end{array}$ & $\begin{array}{c}\text { PRECIO } \\
\text { MAXIMO por Kg }\end{array}$ & $\begin{array}{l}\text { INGRESOS } \\
\text { por Ha. }\end{array}$ \\
\hline \multicolumn{9}{|l|}{ INGRESO POR MERCADO } \\
\hline MMR & $\$ 0,18$ & $\$ 1.080,00$ & $\$ 0,28$ & $\$ 1.680,00$ & $\$ 0,25$ & $\$ 1.500,00$ & $\$ 0,37$ & $\$ 2.220,00$ \\
\hline MMG & $\$ 0,20$ & $\$ 1.200,00$ & $\$ 0,37$ & $\$ 2.220,00$ & $\$ 0,38$ & $\$ 2.280,00$ & $\$ 0,56$ & $\$ 3.360,00$ \\
\hline COSTOTOTAL & $\$ 0,05$ & $\$ 1.523,00$ & $\$ 0,05$ & $\$ 1.523,00$ & $\$ 0,05$ & $\$ 1.523,00$ & $\$ 0,05$ & $\$ 1.523,00$ \\
\hline RENTABILIDAD & \multicolumn{2}{|c|}{ mínimo } & \multicolumn{2}{|c|}{ PROMEDIO } & \multicolumn{2}{|c|}{ MODA } & \multicolumn{2}{|c|}{ MÁXIMO } \\
\hline MMR & \multicolumn{2}{|c|}{$(\$ 443,00)$} & \multicolumn{2}{|c|}{$\$ 157,00$} & \multicolumn{2}{|c|}{$(\$ 23,00)$} & \multicolumn{2}{|c|}{$\$ 697,00$} \\
\hline MMG & \multicolumn{2}{|c|}{$(\$ 323,00)$} & \multicolumn{2}{|c|}{$\$ 697,00$} & \multicolumn{2}{|c|}{$\$ 757,00$} & \multicolumn{2}{|c|}{$\$ 1.837,00$} \\
\hline RENDIMIENTO EN Kg/Ha. & \multicolumn{8}{|l|}{6000} \\
\hline
\end{tabular}

REAL (se determina en función de información primaria de productores)

\begin{tabular}{|c|c|c|c|c|c|c|c|c|}
\hline DESCRIPCIÓN & $\begin{array}{c}\text { PRECIO } \\
\text { MINIMO POI Kg. }\end{array}$ & $\begin{array}{l}\text { INGRESOS } \\
\text { porHa. }\end{array}$ & $\begin{array}{c}\text { PRECIO } \\
\text { PROMEDIO por } \\
\text { Kg. }\end{array}$ & $\begin{array}{l}\text { INGRESOS } \\
\text { porHa. }\end{array}$ & $\begin{array}{l}\text { PRECIO MODA } \\
\text { pOrKg. }\end{array}$ & $\begin{array}{l}\text { INGRESOS } \\
\text { porHa. }\end{array}$ & $\begin{array}{c}\text { PRECIO } \\
\text { MA XIMO por Kg }\end{array}$ & $\begin{array}{l}\text { INGRESOS } \\
\text { porHa. }\end{array}$ \\
\hline \multicolumn{9}{|l|}{ INGRESO POR MERCADO } \\
\hline MMR & $\$ 0,18$ & $\$ 1.186,38$ & $\$ 0,28$ & $\$ 1.845,48$ & $\$ 0,25$ & $\$ 1.647,75$ & $\$ 0,37$ & $\$ 2.438,67$ \\
\hline MMG & $\$ 0,20$ & $\$ 1.318,20$ & $\$ 0,37$ & $\$ 2.438,67$ & $\$ 0,38$ & $\$ 2.504,58$ & $\$ 0,56$ & $\$ 3.690,96$ \\
\hline COSTOTOTAL & $\$ 0,02$ & $\$ 450,00$ & $\$ 0,02$ & $\$ 450,00$ & $\$ 0,02$ & $\$ 450,00$ & $\$ 0,02$ & $\$ 450,00$ \\
\hline RENTABILIDAD & \multicolumn{2}{|c|}{ mínimo } & \multicolumn{2}{|c|}{ PROMEDIO } & \multicolumn{2}{|c|}{ MODA } & \multicolumn{2}{|c|}{ MÁXIMO } \\
\hline MMR & \multicolumn{2}{|c|}{$\$ 736,38$} & \multicolumn{2}{|c|}{$\$ 1.395,48$} & \multicolumn{2}{|c|}{$\$ 1.197,75$} & \multicolumn{2}{|c|}{$\$ 1.988,67$} \\
\hline MMG & \multicolumn{2}{|c|}{$\$ 868,20$} & \multicolumn{2}{|c|}{$\$ 1.988,67$} & \multicolumn{2}{|c|}{$\$ 2.054,58$} & \multicolumn{2}{|c|}{$\$ 3.240,96$} \\
\hline RENDIMIENTO EN KE/ Ha. & 6591 & & & & & & & \\
\hline
\end{tabular}

Fuente: MAGAP, Cotización de precios 2011. INIAP Santa Catalina. Encuesta en la Feria de Guamote 2013 Elaborado por: Mayra Beltrán Morales, Alfredo Altamirano Ulloa 
LA ESTRUCTURA DE LA COMERCIALIZACIÓN, FINANCIAMIENTO

Y TRANSPORTE DE LOS PRINCIPALES PRODUCTOS AGRÍCOLAS Y

SU RENTABILIDAD PARA LOS AGRICULTORES DEL CANTÓN GUAMOTE

GRÁFICO 23

ESCENARIOS REAL DE RENTABILIDAD DE HABA

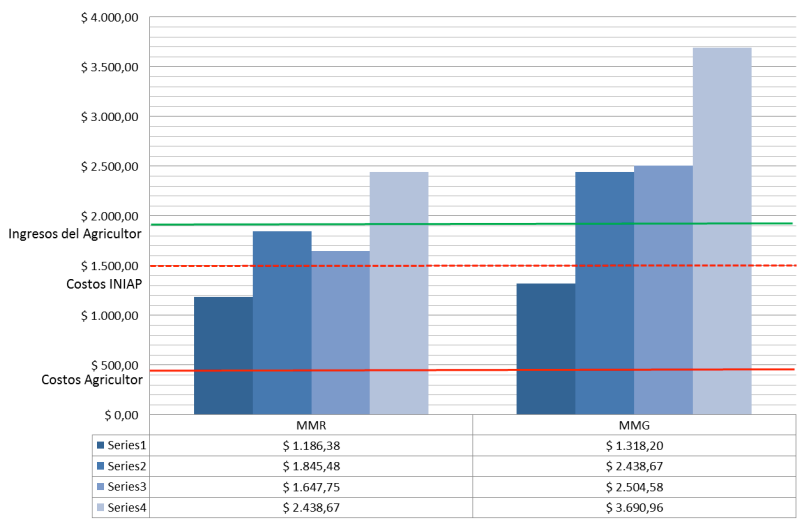

Fuente: MAGAP, Cotización de precios 2011. INIAP Santa Catalina

Elaborado por: Mayra Beltrán Morales, Alfredo Altamirano Ulloa

Para el caso del Haba (ver tabla 26), en el escenario óptimo se aprecia que el rendimiento que establece el INIAP es de $6.000 \mathrm{Kg} / \mathrm{Ha}$ con una inversión de 1.523 dólares, mientras que en el real se alcanza $6.591 \mathrm{Kg} / \mathrm{Ha}$ con una inversión de 450 dólares. Apenas con una tercera parte de inversión, se obtiene mayor cantidad de producto por hectárea sin aplicar las recomendaciones técnicas para el cultivo; esto podría significar que este tipo de cultivos se realiza a costa de la depredación de vegetación natural, pues en estas condiciones los rendimientos del suelo son altos por su fertilidad. Como se muestra en el escenario óptimo, el requerimiento técnico que implica un costo de producción por hectárea de 1.523 dólares genera pérdida en la mayoría de los casos (moda) y cuando los precios de mercado están bajos (mínimo).

Para Guayaquil, con excepción del precio mínimo, en todos los demás escenarios el negocio de la intermediación es rentable. De acuerdo con la información de campo con una inversión mínima de 450 dólares y altos rendimientos, el agricultor sí obtiene una rentabilidad, aunque sujeta a la variación de precios de mercado. (ver gráfico 23). Un elemento adicional es que este producto tiene una sola cosecha al año, por lo cual esta rentabilidad debería reinvertirse en la siembra del año siguiente y en cubrir las necesidades básicas de la familia, con valores que están por debajo del salario mínimo vital, lo cual les mantiene en condiciones de pobreza. 
ReVista PUCE. ISSN 1390-7719. Núm.103. 3 de mayo de 2016-

3 De noviembre de 2016. Alfredo Altamirano UlLoa, Mayra Beltrán MORALES. PP. $185-231$

TABLA 27

RENTABILIDAD DEL MAÍZ SUAVE CHOCLO ÓPTIMO

(Se determina en función del rendimiento establecido por el INIAP)

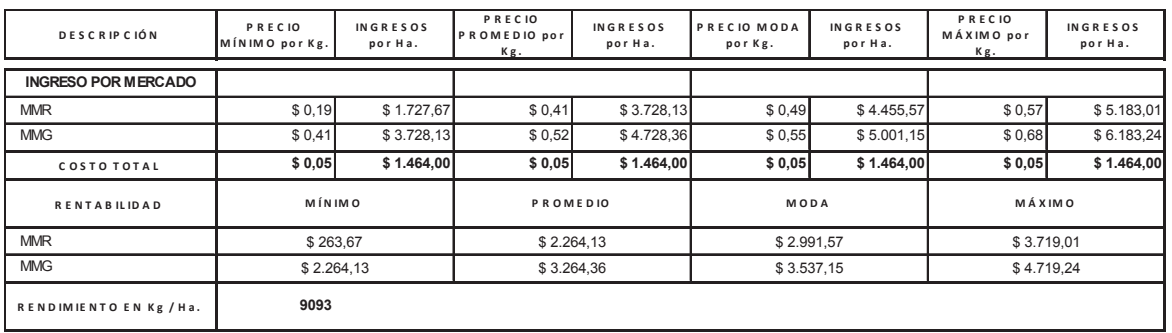

REAL (se determina en función de información primaria de productores)

\begin{tabular}{|c|c|c|c|c|c|c|c|c|}
\hline DESCRIP C IÓN & $\begin{array}{c}\text { PRECIO } \\
\text { MINIMO por Kg. }\end{array}$ & $\begin{array}{l}\text { INGRESOS } \\
\text { porHa. }\end{array}$ & \begin{tabular}{|c|} 
PRECIO \\
PROMEDIO por \\
Kg. \\
\end{tabular} & $\begin{array}{l}\text { INGRESOS } \\
\text { porHa. }\end{array}$ & $\begin{array}{c}\text { PRECIO MODA } \\
\text { por Kg. }\end{array}$ & $\begin{array}{l}\text { INGRESOS } \\
\text { porHa. }\end{array}$ & $\begin{array}{c}\text { PRECIO } \\
\text { MÁXIMO por } \\
\text { Kg. }\end{array}$ & $\begin{array}{l}\text { INGRESOS } \\
\text { porHa. }\end{array}$ \\
\hline \multicolumn{9}{|l|}{ INGRESO POR MERCADO } \\
\hline MMR & $\$ 0,19$ & $\$ 489,44$ & $\$ 0,41$ & $\$ 1.056,16$ & $\$ 0,49$ & $\$ 1.262,24$ & $\$ 0,57$ & $\$ 1.468,32$ \\
\hline MMG & $\$ 0,41$ & $\$ 1.056,16$ & $\$ 0,52$ & $\$ 1.339,52$ & $\$ 0,55$ & $\$ 1.416,80$ & $\$ 0,68$ & $\$ 1.751,68$ \\
\hline COSTOTOTAL & $\$ 0,01$ & $\$ 261,00$ & $\$ 0,01$ & $\$ 261,00$ & $\$ 0,01$ & $\$ 261,00$ & $\$ 0,01$ & $\$ 261,00$ \\
\hline RENTABILIDAD & \multicolumn{2}{|c|}{ MINIMO } & \multicolumn{2}{|c|}{ PROMEDIO } & \multicolumn{2}{|c|}{$M O D A$} & \multicolumn{2}{|c|}{ MÁXIMO } \\
\hline MMR & \multicolumn{2}{|c|}{$\$ 228,44$} & \multicolumn{2}{|c|}{$\$ 795,16$} & \multicolumn{2}{|c|}{$\$ 1.001,24$} & \multicolumn{2}{|c|}{$\$ 1.207,32$} \\
\hline MMG & \multicolumn{2}{|c|}{$\$ 795,16$} & \multicolumn{2}{|c|}{$\$ 1.078,52$} & \multicolumn{2}{|c|}{$\$ 1.155,80$} & \multicolumn{2}{|c|}{$\$ 1.490,68$} \\
\hline RENDIMIENTOEN Kg/Ha. & 2576 & & & & & & & \\
\hline
\end{tabular}

Fuente: MAGAP, Cotización de precios 2011. INIAP Santa Catalina. Encuesta en la Feria de Guamote 2013 Elaborado por: Mayra Beltrán Morales, Alfredo Altamirano Ulloa

GRÁFICO 24

ESCENARIOS REAL DE RENTABILIDAD DEL MAÍZ SUAVE

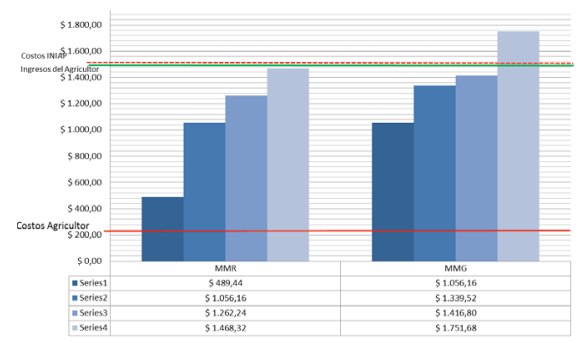

Fuente: MAGAP, Cotización de precios 2011.

INIAP E. E. Santa Catalina

Elaborado por: Mayra Beltrán Morales, Alfredo Altamirano Ulloa
Igualmente, en el escenario óptimo del maíz suave choclo (ver tabla 27), el costo de producción por hectárea que establece el INIAP está en 1.464 dólares para rendimientos de $9.093 \mathrm{Kg} / \mathrm{Ha}$ mientras que en el real, los costos de producción están alrededor de 261 dólares con un rendimiento de $2.576 \mathrm{Kg} / \mathrm{Ha}$. (ver gráfico 24). La rentabilidad del agricultor en este producto también debe distribuirse para todo el año ya que existe solo una cosecha al año. Llama la atención que los ingresos más altos son menores a los costos que el INIAP establece como recomendación técnica. 


\section{CONCLUSIÓN}

En el cantón se evidencia que la población se mantiene del cultivo de los mismos productos transitorios, lo cual revela que su economía es dependiente de la agricultura como se aprecia en el gráfico 25 , donde el $78 \%$ de la PEA se dedica a estas actividades, que no busca usar eficientemente factores productivos, ni genera economías de escala para incrementar y mejorar su competitividad, por lo cual los productores enfrentan una variedad de factores socioeconómicos que los someten a una economía de subsistencia; entre estos resalta la condición de extrema pobreza generalizada que incide en el núcleo familiar al tener que concentrarse en cubrir las necesidades básicas inmediatas por lo cual empeña su futuro, que se agrava por los niveles de producción marginales en parcelas de terreno cada vez más pequeñas, que inciden en el bajo volumen de producción.

En este contexto, el agricultor se encuentra en un estado de alta vulnerabilidad debido al sistema de producción precaria imperante y una explotación extensiva de los recursos naturales que sacrifica la sostenibilidad de los mismos y no permite el desarrollo de la población, no se evidencia un proceso de crecimiento y cambio estructural en su economía, se puede decir que la comu- nidad se resiste a innovar su sistema de producción y trabaja en función de su tradición agrícola y sus limitados recursos humanos.

\section{GRÁFICO 25}

ACTIVIDADES DE LA PEA Y CONCENTRACIÓN DE LA PRODUCCIÓN

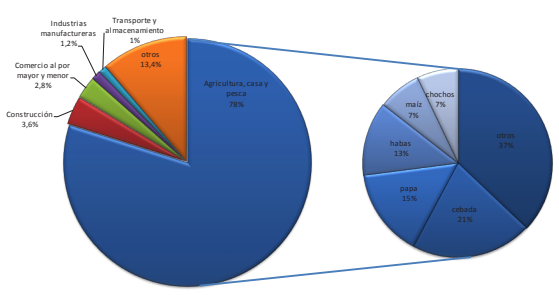

Fuente: GAD GUAMOTE- Encuesta de Línea Base 2010

Elaborado por: Mayra Beltrán Morales, Alfredo Altamirano Ulloa

A esto se deben agregar las dificultades de conectividad y transporte para los integrantes de las comunidades y sus productos hacia la feria y los centros de acopio; los productores no tienen acceso a medios de transporte propio, lo cual genera dependencia de los pocos que si lo tienen y de los intermediarios, que además son dueños de grandes extensiones de tierra, del capital y de los medios de transporte relacionados con el proceso de comercialización; hay que añadir las características del sistema de 
Revista PUCE. ISSN 1390-7719. Núm.103. 3 de mayo de 2016 -

3 De noviembre de 2016. Alfredo Altamirano UlLoa, Mayra Beltrán MORALES. PP. $185-231$

vialidad existente que es muy precario, sus condiciones físicas dificultan la movilidad de personas, productos e insumos y mantienen a las comunidades más alejadas de la capital cantonal en desventaja frente a las cercanas en el proceso de generación de ingresos; esto produce condiciones de inequidad entre los productores y no contribuyen para construir los mínimos necesarios para el bienestar básico de la sociedad local. Además, existe una topografía difícil para la construcción, uso y mantenimiento de las vías que son hechas en buena parte por los habitantes de la zona a través del sistema de mingas y no por las instituciones competentes, lo cual demuestra debilidad institucional en el manejo político de las autoridades del cantón y la provincia.

Estas condiciones se agravan por la inexistencia de capital de operación; los productores no tienen capacidad de acumular capital, tampoco pueden acceder a financiamiento pues no califican como agentes de crédito y los pocos que lo hacen enfrentan costos financieros altos que no pueden cubrir; por lo tanto, es imposible la reinversión para mejorar la producción y de alguna forma mejorar su competitividad.

Además, los intermediarios y comerciantes del cantón que equivalen al 2,8\% de la población económicamente activa, a pesar de ser un porcentaje pequeño, juega un rol relevante en el sistema de comercialización; en alguna medida propician una suerte de economía de escala que reducen sus costos de transacción e incrementa sus rendimientos al concentran la rentabilidad de la producción agrícola en muy pocas manos con una realidad socioeconómica distinta, puesto que al cumplir un rol concentrador de la producción para comercializarla, demostrarían que poseen algún nivel de visión empresarial, a más de facilidades de transporte y movilidad entre los productores y los mercados mayoristas. Estas sí son condiciones que favorecen la acumulación de capital, además que no asumen riesgos en el proceso productivo, se puede decir que construyen un sistema rentable que se sustenta en la explotación de los más pobres; eso sería la consecuencia por separarse de su proceso de organización social tradicional local. 
LA ESTRUCTURA DE LA COMERCIALIZACIÓN, FINANCIAMIENTO

Y TRANSPORTE DE LOS PRINCIPALES PRODUCTOS AGRÍCOLAS Y

SU RENTABILIDAD PARA LOS AGRICULTORES DEL CANTÓN GUAMOTE

\section{BIBLIOGRAFÍA}

ACCION SOCIAL. Cooperativa de ahorro y crédito, Información socio-económica de Guamote. Recuperado de: www.acciónrural.com/index. php?option=com. content\&article\&id=33\&itemid $=122$.

ADITAL. (2008) La emigración ecuatoriana y las nubes de Chimborazo. Ecuador. Recuperado de: http:// www.adital.com.br/site/noticia. asp?lang $=$ es\&cod $=33004$

Arocena J. (2002). El desarrollo local, Un desafío contemporáneo, Taurus, Universidad Católica, segunda edición.

BANCO CENTRAL DEL ECUADOR. (2012). Evolución del Crédito y Tasas de Interés Efectivas Referenciales. Enero 2011 Recuperado de: http:// www.bce. fin.ec/documentos/ Estadisticas/SectorMonFin/BoletinTasasInteres/ect201101.pdf

Bebbington A. (2011), Los espacios públicos de concertación local y sus límites en un municipio indígena: Guamote, Ecuador. Recuperado de: http://www.cepes.org.pe/ debate/debate40-41/16-Bebbington.pdf.

Cameron J. Democracia municipal y desarrollo rural en la sierra ecuatoriana, CENTRO DE ESTUDIOS LATINOAMERICANOS, (2003). Impactos del neolibe- ralismo, Editorial Abya-yala, Quito-Ecuador

Chuquimarca L. (2008). Análisis de la transmisión de los sistemas productivos agrícolas en la sierra ecuatoriana: una aproximación desde la economía ecológica.

COMITÉ DE DESARROLLO LOCAL, Documento base para la elaboración del Plan Participativo de Desarrollo del Cantón Guamote,

COOTAD, CAP II, ARTICULO 40 LITERAL e) DIARIO LOS ANDES, (2011). Vialidad mejora en Guamote con apoyo de la municipalidad. Recuperado de: http://www.diariolosandes.com. ec/content/ view/22233/38/.

DUQUE G. y Genta N. (2011). Crisis y migración: ¿el retorno esperado o búsqueda de alternativas? Flacso sede Ecuador, sistema de información sobre migraciones andinas,

EL COMERCIO, (2010). El invierno deja 3 muertos en el centro de la serranía. Recuperado de: http://www. elcomercio.com/pais/invierno-deja- muertos-centro-Serrania_0_469753036.html,

Espina. A. (1994). La estrategia de Hirschman revisitada. Claves, No. 39 enero-febrero. Recuperado de: http://pendientedemigracion. ucm.es/ centros/cont/ descargas/documento2714.pdf 
Revista PUCE, ISSN 1390-7719. Núm.103. 3 de mayo de 2016 -

3 de noviembre de 2016. Alfredo Altamirano Ulloa, Mayra Beltrán MORALES. PP. $185-231$

Falconí J. (2010). Facultad Latinoamericana de Ciencias Sociales sede Ecuador, Migración interna en el Ecuador y los factores asociados al mercado laboral.

FAO. (2009). Guía para la descripción de suelos, Cuarta edición. Traducido y adaptado al castellano por Ronald Vargas Rojas (Proyecto FAOSWALIM, Nairobi, Kenya-Universidad Mayor de San Simón, Bolivia). Organización De Las Naciones Unidas para la Agricultura y la Alimentación. Roma. Recuperado de: ftp://ftp.fao.org/docrep/fao/011/a0541s/a0541s00. pdf

FAO. (2012). Conservación de los recursos naturales para una Agricultura sostenible, Evaluación del suelo. Recuperado de: http://www.fao.org/ ag/ca/Training_ Materials/ CD27Spanish/se/soil_assessment.pdf

GAD GUAMOTE. (2011). Base de Datos de la encuesta de línea base.

GOBIERNO AUTÓNOMO DESCENTRALIZADO DE LA PROVINCIA DE CHIMBORAZO, (2011). Plan de desarrollo y ordenamiento territorial de Chimborazo, Documento de línea base.

GOBIERNO AUTÓNOMO DESCENTRALIZADO DE LA PROVINCIA DE CHIMBORAZO, (2011). Segunda minga por Chimborazo, Diapositivas plan de gobierno.

GTI INTERCULTURALIDAD. (2008). Línea de base de la Ventanilla para el Programa desarrollo y diversidad cultural para la reducción de la pobreza y la inclusión social.

Herrera G. (2003). La migración vista desde el lugar de origen. revista de ciencias sociales, ICONOS, Flacso sede Ecuador.

ILUSTRE MUNICIPALIDAD DE GUAMOTE, (2011). Alcalde de Guamote rindió cuentas ante los dirigentes de las comunidades y organizaciones. Recuperado de: http:// www.municipiodeguamote.gob. ec/home/secciones. . hhp?idn $=46$ \&id. $\sec =8$,

ILUSTRE PARLAMENTO INDÍGENA Y POPULAR MUNICIPIO DE GUAMOTE, COMITÉ DE DESARROLLO LOCAL, (2001). Documento base para la elaboración del Plan Participativo de Desarrollo del Cantón Guamote, INEC. (2000). Censo agrícola

INEC, (2007), Caracterización del productor agropecuario ecuatoriano.

INEC, (2010). Censo Nacional

INIAP. Objetivos. Recuperado de: http:// www.iniap.gob.ec/nsite/index.php? option=com_content\&view=category \&layout=blog\&id=138\&ltemid=324. 
LA ESTRUCTURA DE LA COMERCIALIZACIÓN, FINANCIAMIENTO

Y TRANSPORTE DE LOS PRINCIPALES PRODUCTOS AGRÍCOLAS Y

SU RENTABILIDAD PARA LOS AGRICULTORES DEL CANTÓN GUAMOTE

La emigración ecuatoriana y las nubes del Chimborazo. Recuperado de: http://www.combats-magazine. org/spip.php?article459.

Larrea C. (2008). Tenencia de la tierra, cambios agrarios y etnicidad indígena en el Ecuador: 1954-2000. Corporación Editora Nacional, Quito

Korovkin T, (2008). La reforma agraria y las comunidades indígenas campesinas en Chimborazo, Corporación Editora Nacional, Quito.

Morales y Estévez. (2006). El páramo: ¿ecosistema en vía de extinción? Departamento de Biología. Facultad de Ciencias Exactas y Naturales. Universidad de Caldas, Revista Luna Azul, No. 22, enero - junio 2006 Recuperado de: http://lunazul. ucaldas.edu.co/index2. phpoption=com_content\&tas$k=v i e w \& i d=44 \&$ Itemilunazul. ucaldas.edu.co

MOVIMIENTO DE UNIDAD PLURINACIONAL PACHAKUTIK-NUEVO PAÍS. Recuperado de: http://www.llacta.org/organiz/pachakutik/

MTOP (2011). Sistema integrado de gestión de proyectos

Naciones Unidas, GTI INTERCULTURALIDAD, (2008). Línea de base de la Ventanilla para el programa desarrollo y diversidad cultural para la reducción de la pobreza y la inclusión social, octubre.
Nieto C, (2010). Apuntes de clase.

PARLAMENTO INDÍGENA Y POPULAR DE GUAMOTE, COMITÉ DE DESARROLLO LOCAL, ILUSTRE MUNICIPALIDAD DE GUAMOTE, (2001). Plan participativo de desarrollo del Cantón Guamote

GOBIERNO AUTÓNOMO DESCENTRALIZADO DEL CANTÓN GUAMOTE. Plan Estratégico.

Ramírez, F. Ciudad Centro de Investigaciones Ciudad, La política del desarroIlo local. Innovación institucional, participación y actores de dos cantones indígenas del Ecuador. Quito, CIUDAD, 2001, 69 p (Ensayos FORHUM No. 16) REVISTA GESTIÓN, (2012) agosto

REVISTA LÍDERES, (2011). Recuperado de: http://www.revistalideres.ec/ Customer Files/Lideres/Especiales/2009/septiembre/provincias/ 9chimborazo/provincias9.html

SENPLADES 2000 Mapa uso actual suelo

Siguencia M. (2010). Diseño de una guía de emprendimiento para el plan de retorno voluntario del migrante. Universidad Andina Simón Bolívar, sede Ecuador

SIISE 6.1., (2011). Ficha metodológica. Recuperado de: http://www. siise.gob.ec/Popup Fichas.aspx?$\operatorname{var} 1=$ Educacion\&var2 $=$ ficedu_ E02\&var3=1. 
Revista PUCE, ISSN 1390-7719. Núm.103. 3 de mayo de 2016 -

3 De noviembre de 2016. Alfredo Altamirano UlLoa, Mayra Beltrán Morales. PP. 185-231

SINAGAP-MAGAP (2011). Línea Base Referencial Guamote.

Solo V. (2008). Las contradicciones de las ONG de desarrollo rural. La trayectoria del FEPP en Chimborazo, 1981-2000. Corporación Editora Nacional, Quito

Tello, M. (2006). Las teorías del desarrollo económico local y la teoría y práctica del proceso de descentralización en los países en desarrollo. Recuperado de: http://www.pucp.edu. pe/economia/pdf/DDD247.pdf

Vásquez. A (2000). Desarrollo Económico Local y Descentralización: Aproximación a un marco conceptual. CEPAL. Recuperado de: http:// www.eclac.cl/ publicaciones / xml/8/6058/lcr1964e.pdf

Zambrano N. (2011). "El Efecto de los Agentes Externos en el Fortalecimiento del Capital Social en las Comunidades Rurales de la Provincia de Chimborazo: Parroquia de Tixán", Maestría en Políticas Públicas con Especialidad en Gestión del Desarrollo, FACULTAD LATINOAMERICA DE CIENCIAS SOCIALES "FLACSO".

(2010). Base de datos preliminar de la Agenda de Competitividad de la provincia de Chimborazo. 
